\title{
Glutathione S-transferase A2 (GSTA2) Promotes Hepatocellular Carcinoma Recurrence After Liver Transplantation Through Modulating Reactive Oxygen Species Metabolism
}

\section{Kevin Tak-Pan NG ( $\sim$ ledodes@hku.hk)}

Hong Kong University: University of Hong Kong https://orcid.org/0000-0001-9822-1335

\section{Oscar Wai-Ho Yeung}

HKU: University of Hong Kong

Yin Fan Lam

University of Hong Kong

Jiang Liu

University of Hong Kong

Hui Liu

University of Hong Kong

Li Pang

University of Hong Kong

Xin Xiang Yang

University of Hong Kong

Ji Ye Zhu

University of Hong Kong

Wei yi Zhang

University of Hong Kong

Matthew YH Lau

University of Hong Kong

Wen Qi Qiu

University of Hong Kong

Hoi Chung Shiu

University of Hong Kong

Man Kit Lai

University of Hong Kong

Chung Mau Lo

University of Hong Kong

Kwan Man

University of Hong Kong 


\section{Research}

Keywords: Liver transplantation, Hepatocellular carcinoma, HCC recurrence, GSTA2, ROS

Posted Date: October 29th, 2020

DOI: https://doi.org/10.21203/rs.3.rs-97857/v1

License: (c) (1) This work is licensed under a Creative Commons Attribution 4.0 International License. Read Full License

Version of Record: A version of this preprint was published at Cell Death Discovery on July 21st, 2021. See the published version at https://doi.org/10.1038/s41420-021-00569-y. 


\section{Abstract}

\section{Background}

An inevitable hepatic injury at the early phase after liver transplantation vitally affects the late phase hepatocellular carcinoma (HCC) recurrence. However, their linkage and underlying risk factors of HCC recurrence are unclear. This study aimed to clarify the clinical impact and functional roles of glutathione S-transferase A2 (GSTA2) in affecting HCC recurrence after liver transplantation.

\section{Methods}

Expression significance and prognostic value of hepatic and circulating GSTA2 in HCC recipients were examined. The polymorphism of GSTA2 transcript was analysed by Sanger sequencing. The functions and molecular mechanisms of GSTA2 in the proliferation and metastasis of HCC were characterized by molecular, cellular and animal experiments.

\section{Results}

The GSTA2 expression was significantly correlated with the early phase hepatic and systemic injury and reactive oxygen species (ROS) level after liver transplantation. Importantly, the level of the early phase circulating GSTA2 protein was a significant predictor of HCC recurrence and survival of HCC recipients. Heterogeneous single nucleotide polymorphism at G335C of GSTA2 was significantly associated with poor survival of HCC recipients. The GSTA2 expression was positively correlated with the aggressiveness of HCCs. Overexpression of GSTA2, by endogenous or exogenous approaches, could enhance the proliferation and invasion of HCCs through activating epithelial-mesenchymal-transition promoting proteins. Targeted inhibition of GSTA2 remarkably suppressed the proliferation and metastasis of HCCs. Increased level of GSTA2 could compensate the $\mathrm{H}_{2} \mathrm{O}_{2}$-induced ROS stress and therefore protect the HCC cells from damage. Alteration of GSTA2 expression in HCC cells could influence the activation of ROSassociated JNK and AKT signaling pathways and the expression of ROS-associated genes in responding to the $\mathrm{H}_{2} \mathrm{O}_{2}$ condition.

\section{Conclusions}

Our research discovered GSTA2 to be the significant risk factor of HCC recurrence via providing a favorable ROS environment for HCC to survival and progress. This study presents a novel functional biomarker for combating HCC recurrence after liver transplantation.

\section{Background}

Hepatocellular carcinoma (HCC) is one of the deadliest diseases, being the fourth most common cause of cancer-related death worldwide (1). Liver transplantation (LT) is the best curative treatment to achieve successful survival outcome for HCC patients under selection criteria (2). However, HCC recurrence is a significant challenge in HCC recipients, that is the major reason of poor overall survival after liver 
transplantation $(3,4)$. Although Milan criteria and University of California San Francisco (UCSF) criteria have improved the survival of HCC recipients, these preoperative tumor-based criteria have been becoming less accurate in predicting the risk of $\mathrm{HCC}$ recurrence owing to the emergent expansion of donor pools and selection criteria for liver transplantation in HCC patients (5). Discovery of novel noninvasive biomarkers and the combination of biomarkers could generate more effective prediction systems for HCC recurrence after liver transplantation (5). Moreover, understanding on the mechanisms of this recurred disease should be indispensable for providing clues for identifying novel predictive molecules and developing novel preventive strategies.

Ischemia-reperfusion (I/R) injury is an unavoidable consequence after liver transplantation especially at the early phase. Several lines of clinical and experimental studies have pointed out that $I / R$ injury is a significant risk factor of HCC recurrence after liver transplantation (6-8). Our previous research studies have also demonstrated a positive correlation between early phase hepatic injury and late phase HCC recurrence after liver transplantation. The increased hepatic $\mathrm{l} / \mathrm{R}$ injury can exaggerate liver tumor progression and increase the likelihood of lung metastasis through activations of cell adhesion, invasion, and angiogenesis pathways (9). Elevated early-phase hepatic injury after liver transplantation can alter the microenvironment and signaling pathways that not only favors tumor development but also promotes the invasiveness of tumor cells (10-12). In addition, a panel of circulating microRNAs have been identified to be significantly up-regulated at early phase of HCC recipients who developed with recurred HCC at late phase after liver transplantation (13). Recently, by transcriptome analysis of the early phase liver biopsies, several key pathways and genes have been identified such as adhesion molecules HFE and CD274 whose expression level at early phase shows significant correlation with late phase HCC recurrence after liver transplantation (14). Collectively, understanding on early phase hepatic injury after liver transplantation should provide important clues for future development of prognostic and therapeutic strategies to combat HCC recurrence after liver transplantation.

Hepatic I/R injury is closely linking to production of reactive oxygen species (ROS) whose augmentation is the major initiator in triggering hepatic damage especially in the early stage of I/R process (15). Activation of macrophage during the initial stage of $I / R$ injury is the main source of producing extracellular ROS (16). Moreover, aggravated hepatic I/R injury further elevates the production of ROS from inflammatory cells and mitochondria (16). Generally, cells are composed of three important pathways to eliminate ROS toxicity including reduced glutathione, thioredoxin and catalase $(17,18)$. It is still unclear how these I/R injury-induced ROS-related pathways could affect the recurrence of HCC after liver transplantation.

Glutathione S-transferase A2 (GSTA2) which is a phase II detoxifying enzymes is highly expressed in the liver tissue functioning in detoxification of electrophilic compounds, such as therapeutic drugs, environmental toxins and products of oxidative stress(19). GSTA2 can regulate glutathione utilization to protect cells against ROS damage(19). Overexpression of GSTA2 protects cancer cells against apoptosis from chemotherapeutic drug(20).Polymorphic feature of GSTA2 is associated with different diseases including human cancers $(21-23)$. The role of GSTA2 in HCC is scanty. Upregulation of GSTA2 is 
associated with doxorubicin-resistance of $\mathrm{HCC}(24)$. By RNA sequencing analysis, we identified GSTA2 to be significantly upregulated in the liver biopsies at the post-LT early-phase of HCC recipients who developed recurred HCC. We aimed to characterize the clinical significance and prognostic value of GSTA2 in HCC recipients and to characterize its functions and underlying mechanisms in HCC recurrence and metastasis.

\section{Materials And Methods Patients and samples}

Clinical samples were collected from $106 \mathrm{HCC}$ recipients from Oct 2003 to June 2017 at the time point of 2 hours after reperfusion (early phase) in the liver transplantation operation. The last follow-up date of the recipients was on Mar 2020. There were 106 early phase plasma and 60 early phase liver biopsies were used in this study. Twenty-four liver tissues and 12 plasma samples were from healthy donors in liver transplantation. One-hundred pairs of tumor and non-tumor liver tissues were randomly obtained from HCC patients received hepatectomy. All the clinical samples were obtained from the Surgical Tissue Bank of the Department of Surgery, the University of Hong Kong. A consent form was signed by each patient before sample collection. The use of clinical samples for research purpose was approved by the Institutional Review Board of the University of Hong Kong/Hospital Authority Hong Kong West Cluster (HKU/HA/HKW IRB).

\section{Rat liver tumor tissues}

Rat liver tumor tissues generated from our previous rat liver tumor models were used (9): (1) Less aggressive tumor group, rats were injected with tumor cells without major hepatectomy and partial hepatic I/R; (2) More aggressive tumor group: 60 minutes' ischemia on right and median lobes first, then subsequently did the major hepatectomy for left and caudate lobes (50-60\% of total liver volume). After 60 minutes' reperfusion (right and median lobes), tumor cells were injected via the right portal vein. Liver tumor tissues were collected from the rat after 4-week incubation.

\section{RNA-sequencing analysis of acute phase liver graft in liver transplantation}

RNA-sequencing analysis (14) was previously performed to compare the transcription profile of early phase liver biopsies from $\mathrm{HCC}$ recipients with $(\mathrm{N}=6)$ and without $(\mathrm{N}=5)$ post-transplantation HCC recurrence. Gene expression level between any given two samples was gauged by the number of sequencing data mapped to the gene, RPKM (reads per kilobase per million mapped reads). Each recurrence sample was compared to each non-recurrence sample to identify the up-regulated and downregulated genes.

\section{Sanger Sequencing of GSTA2 transcript}


The full length coding sequence of GSTA2 transcript ( $669 \mathrm{bp}$, encoding 223 amino acids) was amplified by PCR reaction using the FastStart Taq DNA polymerase (Roche) with the PCR condition: $95^{\circ} \mathrm{C}, 10 \mathrm{~min}$ for initiate denaturation; 35 cycles of $95^{\circ} \mathrm{C}, 1 \mathrm{~min} ; 56^{\circ} \mathrm{C}, 30 \mathrm{sec}$, and $72^{\circ} \mathrm{C}, 1 \mathrm{~min}$ for PCR amplification; followed by final extension step of $72^{\circ} \mathrm{C}, 10 \mathrm{~min}$. The primers used for PCR were: forward primer: $5^{\prime}-$ CCCAAGCTCCACTACTCCAATAT-3'; reverse primer: 5'- GCAGCTTGTTCCTCAGGTTGAGTA-3'. The PCR product of GSTA2 coding sequencing of each sample was examined by gel electrophoresis. PCR products were enzymatically cleaned up by Shrimp Alkaline Phosphatase (New England Biolabs) and Exonuclease I (New England Biolabs). Samples were cycle sequenced using BigDye ${ }^{T M}$ Terminator v3.1 Cycle Sequencing Kit (Applied Biosystems) according to the manufacturer's protocol. Sequencing products were purified with BigDye XTerminator ${ }^{\text {TM }}$ Kit (Applied Biosystems) and automated sequencing performed by capillary electrophoresis on an ABI 3730xI DNA Analyzer (Applied Biosystems). The Sanger sequencing analysis were conducted in the Centre for PanorOmic Sciences, LKS Faculty of Medicine, the University of Hong Kong. The Sanger sequencing data were viewed by Sequence Scanner software 1.0 (Applied Biosystems) followed by identification of single nucleotide polymorphism (SNP) by two independent researchers. The SNP genotypes were coded into three groups: homozygous (reference allele, heterozygous, homozygous (variant allele). Chi-square was used to compare difference between recipients with and without HCC recurrence after liver transplantation. $P<0.05$ was considered as statistical significance.

\section{Quantitative RT-PCR}

Total RNAs in the cells or tissue samples were extracted using TRIzol® reagent (Invitrogen; ThermoFisher Scientific, Inc.). RNA was converted to cDNA using a High-Capacity cDNA RT kit (Applied Biosystems;

Thermo Fisher Scientific, Inc.). Quantitative PCR was performed using the Power SYBR Green PCR master mix and quantified using the ViiA7 Real-Time PCR System (Thermo Fisher Scientific, Inc.). 18S ribosomal RNA (rRNA) was used as the internal control for HCC tissue samples and $\beta$-actin was used as the internal control for cell lines. The relative expression levels of genes was determined based on our previous studies $(25,26)$. The primers used in this study were list in Additional File 1 Table S1.

\section{Cell lines and gene cloning}

The human normal liver cell line named MIHA and the Hep3B hepatoma cell line were purchased from American Type Cell Culture (ATCC). The metastatic HCC cell line MHCC97L (97L in short) provided by the Liver Cancer Institute \& Zhongshan Hospital of Fudan University, Shanghai, People's of Republic of China (27). The cell lines were cultured in DMEM high glucose (Gibco; Thermo Fisher Scientific, Inc.) with 10\% FBS (Gibco; Thermo Fisher Scientific, Inc.), 1\% penicillium and streptomycin in a $37^{\circ} \mathrm{C}$ incubator supplied with $5 \% \mathrm{CO}_{2}$.

The lentiviral open reading frame (ORF) clone of monomeric green fluorescent protein (GFP)-tagged human GSTA2 (cat. no. RC202479L2) and lentiviral ORF control clone were purchased from OriGene Technologies, Inc. Lentiviral particles were produced by transfection into HEK293 cells using Lenti-vpak Lentiviral Packaging kit (OriGene Technologies, Inc). Suppression of GSTA2 was conducted by GSTA2- 
specific Mission ${ }^{\circledR}$ short hairpin RNA (shRNA) lentiviral transduction particles (Sigma-Aldrich; Merck $\mathrm{KGaA}$ ). Mission TurboGFP Control transduction particles (Sigma-Aldrich; Merck KGaA) was used as a control. Lentiviral particles were transduced into HCC cells according to the manufacturer's instructions. The expression levels of GSTA2 mRNA and protein was examined by RT-PCR) and Western blot respectively.

\section{Reactive oxygen species (ROS) assay}

The level of a ROS, $\mathrm{H}_{2} \mathrm{O}_{2}$ was measured by the ROS-GloTM $\mathrm{H}_{2} \mathrm{O}_{2}$ Assay kit (Promega). For in vitro experiment, 5000 cells were seeded in a 96-well white plate and incubated in normal culture condition for 24 hours. The cells were treated with $\mathrm{H} 2 \mathrm{O} 2$ for 18 hours under normal culture condition. To perform the assay, the cells were incubated with $25 \mathrm{ul}$ of $\mathrm{H}_{2} \mathrm{O}_{2}$ substrate solution each well for 6 hours. Then $100 \mathrm{ul}$ of ROS-Glo ${ }^{\text {TM }}$ Detection Solution was applied into each well and incubated at room temperature for 20 min. The luminescent signal was quantified by a luminescence plate reader (Bio-Rad). For human serum samples, each 100 ul of serum sample was incubated with 25 ul of $\mathrm{H}_{2} \mathrm{O}_{2}$ substrate solution for 6 hours and followed by same step as done in in vitro experiment.

\section{Apoptosis assay}

Apoptotic cells were stained by In Situ Cell Death Detection Kit (Roche Molecular Biochemicals, Roche Applied Science, Indianapolis, IN, USA). Cells were fixed with ice-cold acetone/methanol (1:1) at $-20^{\circ} \mathrm{C}$ for $10 \mathrm{~min}$. The cells were digested with protease $\mathrm{K}$ solution $(20 \mathrm{ug} / \mathrm{ml})$ at $37^{\circ} \mathrm{C}$ for $30 \mathrm{~min}$. The cells were incubated with Terminal deoxynucleotidyl transferase dUTP nick end labeling (TUNEL) reaction mix at $37^{\circ} \mathrm{C}$ for min. Endogenous peroxidase was blocked by $0.3 \% \mathrm{H}_{2} \mathrm{O}_{2}$ at room temperature for $20 \mathrm{~min}$. POD was applied to the cells and incubated at room temperature for $30 \mathrm{~min}$. The signal was developed by DAB substrate. The apoptotic cells were captured under microscope. Average number of apoptotic cells were calculated from 5 randomly selected fields.

In vivo subcutaneous liver tumor model.

The subcutaneous liver tumor model was performed as previously described $(28)$. HCC cells $\left(1 \times 10^{6}\right)$ were suspended in $100 \mu \mathrm{I}$ of saline and subcutaneously injected into each nude mouse. The tumor size and body weight were measured for every 5 days. After 6 weeks, the mice were sacrificed and the tumors were harvested for further analysis. Four mice were recruited for each of the experimental group. Volume of the tumor was calculated as follows: tumor volume $\left(\mathrm{cm}^{3}\right)=1 / 2 \mathrm{x}$ larger size $\mathrm{x}$ smaller size.

In vivo experimental metastasis model

In vivo experimental metastasis model was performed as previously described (28). Cells $\left(1 \times 10^{6}\right)$ suspended in $100 \mu \mathrm{I}$ of saline into the tail vein of nude mice. All mice were fed in standard condition with weight monitoring and sacrificed after 6-week incubation. Eight mice were recruited for each of the experimental group. To determine lung metastases, 100 consecutive sections $(4 \mu \mathrm{M})$ were cut and 
subsequently stained with $\mathrm{H} \& \mathrm{E}$. The metastatic nodules were examined by an experienced pathologist and a trained researcher.

\section{Immunohistochemistry}

Each $4 \mu \mathrm{M}$-thick paraffin slide was dewaxed in xylene and rinsed in grade alcohol and finally rehydrated in water. Antigen was retrieved by using citric buffer ( $\mathrm{pH}$ 6.0). The slide was blocked with peroxidase block for 20 minutes and $10 \%$ goat serum for 30 minutes respectively. Human GSTA2 antibody (LSC166704, LSBio) was incubated with the slide at $4^{\circ} \mathrm{C}$ for overnight. Secondary antibody from the Envision system (DakoCytomation, Denmark) was applied and incubated with the slide for 30 minutes at room temperature. The signal was developed by DAB substrate solution. The slide was finally counter-stained by hematoxylin solution.

\section{MTT viability assay}

MTT viability assay was performed as described previously (29). HCC cells $\left(5 \times 10^{3}\right.$ cells per well) were seeded into a 96-well plate and incubated for 24 hours. To perform MTT assay, the cells were then incubated with $100 \mu \mathrm{l}$ of $5 \mathrm{mg} / \mathrm{ml}$ MTT solution (Invitrogen; Thermo Fisher Scientific, Inc.) for $3 \mathrm{~h}$ at $37^{\circ} \mathrm{C}$ until crystals were formed. MTT solution was removed from each well and the crystals were dissolved in $100 \mu \mathrm{l}$ DMSO. Color intensity was measured using a microplate reader (Bio-Rad Laboratories, Inc.) at a wavelength of $570 \mathrm{~nm}$. Each experiment consisted of four replicates and at least three individual experiments were performed.

\section{Migration assay}

The wound healing assay was performed in the Culture-Insert 2 Well (Ibidi) culture well which contains two chambers separated by the Culture-Insert 2 Well. HCC cells $\left(3.5 \times 10 \mathrm{e}^{4}\right.$ cells in 70 ul of medium) were seeded into each chamber and incubated for 24 hours in normal culture condition. The Culture-Insert 2 Well was removed to allowed the formation of a gap between cells seeded in the two chambers. The cells were refilled with appropriated volume of medium and continuously cultured for 2 days. The distance of the gap was captured under microscope.

\section{Invasion assay}

Invasion assay was performed by using BD BioCoat ${ }^{\text {TM }}$ BD Matrige $^{\text {TM }}$ Invasion Chamber (BD Biosciences). Briefly, $5 \times 10^{4}$ cells were suspended in $500 \mu$ of serum-free DMEM and seeded into the migration chamber. After 24 hours of incubation, cells on the upper surface of the chamber were scrapped out by a cotton swab. Cells migrated through the chamber were stained by hematoxylin and eosin (H \& E) and subsequently counted under the microscope. At least three independent experiments were performed.

\section{Western blot}

Total protein was extracted from cells by using cell lysis buffer (Cell Signaling Technology, Inc.). Protein lysate was quantified by using Bio-Rad Protein Assay Dye Reagent Concentrate (Bio-Rad Laboratories. Inc.). Western blotting was performed as previously described (28). Briefly, proteins were resolved by SDS- 
PAGE electrophoresis and transferred onto polyvinylidene fluoride membrane (Millipore). The membrane was blocked in $5 \%$ non-fat milk at room temperature for 1 hour. Antibody at proper dilution was incubated with the membrane at $4^{\circ} \mathrm{C}$ for overnight. After 3 times PBS washing, the membrane was incubated with secondary antibody at room temperature for 1 hour. After 3 times PBS washing, protein intensity signal was detected using the ECL Prime Western Blotting Detection kit (GE Healthcare). Antibodies used in this study included GSTA2 (PA5-21670, Invitrogen, Thermo Fisher Scientific), $\beta$-actin (MB1501, Merck KGaA), phospho-AKTser473 (\#9271S, Cell signaling Technologies), AKT (\#9272, Cell signaling Technologies), and Phospho-JNK (\#4671, Cell signaling Technologies).

\section{Elisa assay}

The level of GSTA2 protein in plasma samples was quantified by the human GSTA2 ELISA Kit (Cat. No.: MBS941699, MyBioSources). Briefly, 100 ul of plasma sample was applied to the well of the microtiter plate followed by incubation at $37^{\circ} \mathrm{C}$ for 2 hours. Biotin-antibody solution (100 ul) was added to each well and incubated at $37^{\circ} \mathrm{C}$ for 1 hour. After the washing step, HRP-avidin solution was added to each well and incubated at $37^{\circ} \mathrm{C}$ for 1 hour. After the washing step, the TMB substrate solution was added to each well followed by incubation at $37^{\circ} \mathrm{C}$ for $20 \mathrm{~min}$. The Stop solution was added to each well. The optical density of each well was measured by microplate reader and calculated as: Value at $570 \mathrm{~nm}$ - Value at $450 \mathrm{~nm}$.

\section{Milliplex assay}

The level of cytokines/chemokines in the post-transplant early phase plasma was quantified by using the Milliplex Map Kit (EMD Millipore Corporation, MA). Analytes for detection of 10 cytokines/chemokines including GM-SCF, IFNa2, IFNy, IL-10, IL-1 3 , IL-6, IL-8, IP-10, MCP-1 and TNFa were purchased from the HUMAN CYTOKINE / CHEMOKINE MAGNETIC BEAD PANEL (HCYTOMAG-60K). Each plasma sample $(25 \mathrm{ul})$ and $25 \mathrm{ul}$ of Assay buffer were added to each well of the 96-well micro-plate. The mixed antibodyimmobilized beads $(25 \mathrm{ul})$ was added to the well followed by incubation with shaking $(700 \mathrm{rpm})$ at $4^{\circ} \mathrm{C}$ for overnight. The plate was washed with Washing buffer for 2 times. The Detection buffer ( $25 \mathrm{ul})$ was added into each well and incubated at room temperature for 1 hour. The Streptavidin-phycoerythrin solution ( $25 \mathrm{ul}$ ) was added to each well and incubated at room temperature for $30 \mathrm{~min}$. After 2 times' washing step, the beads were suspended with sheath fluid (150 ul) by shaking for $5 \mathrm{~min}$. The median fluorescent intensity (MFI) for each well was measured by the MAGPIX® machine (Luminex). The concentration of each sample was calculated by a 5-paramter logistic curve-fitting method.

\section{RT ${ }^{2}$ PCR array analysis.}

The expression level of genes critical in oxidative stress was simultaneously analyzed using an $\mathrm{RT}^{2}$ Profiler PCR array (Qiagen Sciences, Inc.)(30). Total RNA extracted from HCC cells was reversetranscribed to $\mathrm{cDNA}$ using the $\mathrm{RT}^{2}$ First Strand kit (Qiagen Sciences, Inc.). Each Real-Time Human Oxidative Stress Plus PCR array plate (cat. no. PAHS-065YA; Qiagen Sciences, Inc.) contained 84 key genes associated with oxidative stress. qPCR was performed using the SYBR Green Master Mix (Qiagen Sciences, Inc.) on a ViiA-7 PCR machine (Thermo Fisher Scientific, Inc.). Gene expression of MHCC97L- 
shGSTA2 cells was calculated as the fold-difference using the $2^{-\triangle \Delta C t}$ method (31) relative to the expression of MHCC97L-control cells. The mean Ct value of commonly used housekeeping genes (GAPDH and $\beta$-actin) was used as the internal control for normalization. The expression correlation between GSTA2 and the identified differential genes was analyzed by using the database of Liver Hepatocellular carcinoma (369 tumor tissues of HCC patients) in the Gene Expression Profiling Interactive Analysis (GEPIA) web server (32).

\section{Statistical analyses}

The column-scatter plots were graphed by Prism Version 5.01 (Graphpad). The bar charts were graphed by Excel (Microsoft). Statistical analyses were performed by SPSS software version 20 (SPSS, Chicago, IL). Categorical variables were analyzed by Chi-square test or Fisher's exact test. Continuous variables were analyzed by Mann-Whitney $U$ test or student $T$ test. The correlation analyses were analyzed by Pearson correlation analysis. To examine the prognostic value of plasma GSTA2 protein, Receiver Operating Characteristic (ROC) curve was generated for predicting tumor recurrence after liver transplantation. The optimal cut-off value of plasma GSTA2 protein was obtained from Youden index, which was used to classify the recipients into to 2 groups: High GSTA2 and Low GSTA2 groups. The sensitivity and specificity of plasma GSTA2 protein to predict HCC recurrence after liver transplantation was determined by ROC analysis. Logistic regression analysis was performed on significant factors in predicting post-LT HCC recurrence. Kaplan-Meier analysis applying log-rank test was performed to analyze the prognostic value of plasma GSTA2 protein in predicting overall and disease-free survival of HCC recipients after liver transplantation. Univariate Cox Proportional Hazardous Regression analysis was performed to examine the hazard ratio of plasma GSTA2 protein or clinical factors in predicting overall and disease-free survival of HCC recipients. Multivariate Cox Proportional Hazardous Regression analysis was performed to compare the significant factors in univariate cox-regression analysis. $P<0.05$ was considered as statistically significant.

\section{Results}

\section{Identification of GSTA2 as a HCC-recurrence associated gene at early-phase after liver transplantation}

RNA sequencing was previously performed on liver biopsies collected from early phase after liver transplantation (2 hours after portal vein reperfusion) (14). To identify differentially expressed earlyphase genes associated with late-phase HCC recurrence, the transcription profile of the liver biopsies from the recurrent recipients $(\mathrm{N}=6)$ was compared to the non-recurrent recipients $(\mathrm{N}=5)$ through a one-by-one comparison approach. There were 7 upregulated and 30 downregulated genes identified. GSTA2 was the most upregulated gene in the HCC recipients with HCC recurrence compared to non-HCC recurrent recipients (Additional file 1, Table S2). The expression level of GSTA2 mRNA was further examined in the 58 recipients' liver biopsies. Compared to the livers from healthy donors, the expression level of hepatic GSTA2 mRNA at post-LT early phase was significantly higher than in the livers from healthy donors 
(Fig. 1a). The expression level of hepatic GSTA2 mRNA in recurrent recipients was higher than in nonrecurrent recipients, but a statistical significance could not achieve (Fig. 1b). When classifying the types of liver transplantation into deceased donor liver transplantation (DDLT) and living donor liver transplantation (LDLT), a significantly higher expression level of GSTA2 mRNA was determined in LDLT recurrent recipients compared to DDLT non-recurrent recipients (Fig. 1c). A higher level of GSTA2 protein was detected in the liver of recurrent recipients after LDLT than in non-recurrent recipients after DDLT (Fig. 1d). Upregulation of hepatic GSTA2 mRNA at early phase after liver transplantation was found to be significantly correlated with the expression level of genes related to reactive oxygen species (ROS) metabolism (GPX2, GPX3, SOD3 and NRF2 mRNAs) and hepatic injury (TNFa and TGF 3 mRNAs) (Fig. 1e).

\section{Early phase circulating GSTA2 ( EPC GSTA2) protein was an indicator of hepatic injury and a prognostic biomarker of HCC recurrence after liver transplantation}

The concentration of post-LT ${ }_{\text {EPC }}$ GSTA2 protein was examined in $106 \mathrm{HCC}$ recipients. A significantly

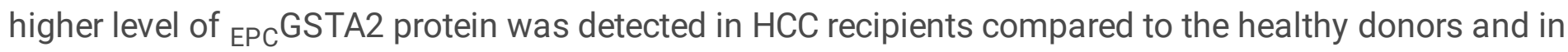
pre-transplant plasma of the recipients (Fig. 2a). The concentration of EPCGSTA2 protein was not significantly correlated with the pre-transplantation clinicopathological characteristics of the recipients including sex, age, HBV surface antigen (HbsAg), Milan criteria, UCSF criteria, AFP level, graft types, AST and ALT levels (Table 1). Interestingly, the concentration of EPCGSTA2 protein was significantly correlated with the duration of warm ischemic time and the level of AST and ALT after liver transplantation

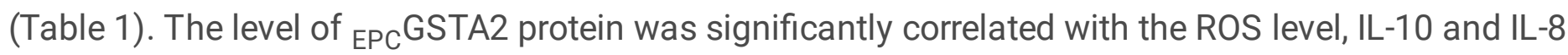
proteins in early phase plasma of HCC recipients (Table 1). 
Table 1

Statistical analysis of early phase GSTA2 protein with clinical and experimental variables of HCC recipients

\begin{tabular}{|c|c|c|}
\hline Variables & Early phase GSTA2 & $P$ value \\
\hline \multicolumn{3}{|l|}{ (1) Pre-Transplantation } \\
\hline \multicolumn{3}{|l|}{ - Sex } \\
\hline Male $(\mathrm{N}=88)$ & $486.6(183.9-718.4)$ & \multirow[t]{2}{*}{0.160} \\
\hline Female $(N=18)$ & $436.7(160.9-941.1)$ & \\
\hline \multicolumn{3}{|l|}{ • Age } \\
\hline$<=57$ & $484.3(230.0-941.1)$ & \multirow[t]{2}{*}{0.493} \\
\hline$>57$ & $478.5(160.9-667.8)$ & \\
\hline \multicolumn{3}{|l|}{ - HbsAg before LT } \\
\hline Positive (N = 85) & $486.3(160.9-941.1)$ & \multirow[t]{2}{*}{0.252} \\
\hline Negative $(N=21)$ & $455.6(230.0-667.8)$ & \\
\hline \multicolumn{3}{|l|}{ • Milan criteria } \\
\hline Within $(N=59)$ & $477.8(160.9-718.4)$ & \multirow[t]{2}{*}{0.233} \\
\hline Beyond ( $N=47)$ & $496.9(183.9-941.1)$ & \\
\hline \multicolumn{3}{|l|}{ • UCSF criteria } \\
\hline Within $(N=74)$ & $470.2(160.9-718.4)$ & \multirow[t]{2}{*}{0.173} \\
\hline Beyond ( $N=32$ ) & $499.1(183.9-941.1)$ & \\
\hline \multicolumn{3}{|l|}{ • AFP level before LT } \\
\hline$<=400 \mathrm{ng} / \mathrm{ml}(\mathrm{N}=89)$ & $477.0(160.9-941.1)$ & \multirow[t]{2}{*}{0.615} \\
\hline$>400$ ng/ml (N = 17) & $496.9(242.0-632.2)$ & \\
\hline \multicolumn{3}{|l|}{ - Type of graft } \\
\hline Live graft $(\mathrm{N}=81)$ & $477.0(160.9-718.4)$ & \multirow[t]{2}{*}{0.529} \\
\hline Cadaveric graft $(\mathrm{N}=25)$ & $501.4(256.5-941.1)$ & \\
\hline - Graft weight to Recipient ESLV (\%) & $R=0.113$ & 0.248 \\
\hline • Pre-LT AST (u/l, N = 106) & $R=0.127$ & 0.195 \\
\hline - Pre-LT ALT (u/l, N = 106) & $R=0.067$ & 0.495 \\
\hline
\end{tabular}




\begin{tabular}{|c|c|c|}
\hline Variables & Early phase GSTA2 & $P$ value \\
\hline - Cold ischemic time $(\mathrm{min})(\mathrm{N}=106)$ & $R=0.182$ & 0.062 \\
\hline - Warm ischemic time $(\min (N=104)$ & $R=0.218$ & $0.026 *$ \\
\hline - Post-LT ROS level $(\mathrm{N}=69)$ & $R=0.578$ & $0.000 * \star \star$ \\
\hline - Post - LT AST (u/l, N = 106) & $R=0.268$ & $0.022^{\star}$ \\
\hline - Post-LT ALT (u/l, N = 106) & $R=0.300$ & $0.031^{*}$ \\
\hline - Post-LT bilirubin (mg/dl, $\mathrm{N}=72$ ) & $R=0.037$ & 0.758 \\
\hline - Post-LT-2hr GM-CSF $(\mathrm{N}=100)$ & $R=-0.108$ & 0.283 \\
\hline - Post-LT-2hr IFN-alpha2 $(\mathrm{N}=100)$ & $R=0.060$ & 0.550 \\
\hline - Post-LT-2hr IFN-gamma ( $=100)$ & $R=0.030$ & 0.768 \\
\hline - Post-LT-2hr IL-10 (N = 100) & $R=0.359$ & $0.000 * \star \star$ \\
\hline - Post-LT-2hr IL-6 (N = 100) & $R=0.052$ & 0.606 \\
\hline - Post-LT-2hr IL-8 (N = 100) & $R=0.306$ & $0.002^{\star *}$ \\
\hline - Post-LT-2hr IP-10 (N = 100) & $R=0.120$ & 0.234 \\
\hline - Post-LT-2hr MCP-1 (N = 100) & $R=0.105$ & 0.297 \\
\hline - Post-LT-2hr TNF-alpha $(\mathrm{N}=100)$ & $R=0.026$ & 0.795 \\
\hline - Post-LT-2hr miR-148a $(\mathrm{N}=56)$ & $R=0.123$ & 0.365 \\
\hline - Post-LT-2hr miR-1246 ( $N=56)$ & $R=0.281$ & $0.036^{\star}$ \\
\hline - Post-LT-2hr miR-1290 (N = 56) & $R=0.215$ & 0.112 \\
\hline
\end{tabular}

Attractively, recipients with post-LT HCC recurrence were detected with a significantly higher concentration of ${ }_{E P C} G S T A 2$ protein compare to recipients without developing $\mathrm{HCC}$ recurrence after liver transplantation (Fig. 2b). Furthermore, EPCGSTA2 protein was significant correlated with early phase plasma miR-1246 level (Table 1), which has been previously demonstrated to be significantly associated with post-

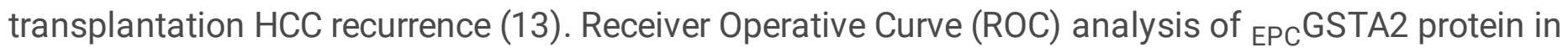
discriminating post-LT HCC recurrence showed to have the area under curve (AUC) value of $0.752(P=$ 0.000 , Fig. 2c). The determined optimal cut-off value of the concentration of ${ }_{\text {EPC }}$ GSTA2 protein in

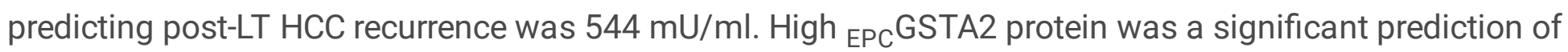
post-LT HCC recurrence of recipients (Sensitivity $=0.542$; Specificity $=0.854 ; p=0.003 ;$ Fig. $2 d$ ). Among those significant factors, EPCGSTA2 protein and UCSF criteria were independent predictors in predicting post-LT HCC recurrence (Table 2). Moreover, EPCGSTA2 protein was significantly associated with poor ease-free survival (Fig. 2e) of HCC recipients. The ${ }_{\text {EPC }}$ GSTA2 protein was also a significant predictor of 


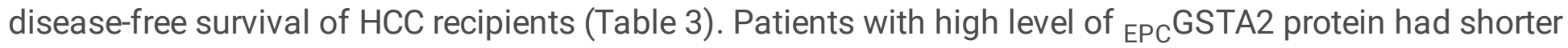
overall survival rate than low level of High level of ${ }_{\text {EPC }}$ GSTA2, but the difference was not statistically significant (Fig. 2f).

Table 2

Receiver Operating Characteristic and Logistic regression analyses variables in predicting HCC recurrence after liver transplantation.

\begin{tabular}{|c|c|c|c|c|c|c|}
\hline \multicolumn{5}{|c|}{ ROC analysis } & \multicolumn{2}{|c|}{$\begin{array}{l}\text { Logistics } \\
\text { Regression }\end{array}$} \\
\hline Variables & Sensitivity & Specificity & AUC $(95 \% \mathrm{Cl})$ & $P$ value & $\mathrm{HR}$ & $P$ value \\
\hline $\begin{array}{l}\text { - Early phase } \\
\text { plasma GSTA2 } \\
\text { protein (High vs low) }\end{array}$ & $45.8 \%$ & $85.4 \%$ & $\begin{array}{l}0.698(0.567- \\
0.828)\end{array}$ & $0.003^{\star \star}$ & 9.034 & $0.002^{\star \star}$ \\
\hline $\begin{array}{l}\text { - Milan Criteria } \\
\text { (Beyond } v s \text { within) }\end{array}$ & $83.3 \%$ & $67.1 \%$ & $\begin{array}{l}0.752 \\
(0.645- \\
0.859)\end{array}$ & $0.000 * * *$ & 1.046 & 0.966 \\
\hline $\begin{array}{l}\text { - UCSF criteria } \\
\text { (Beyond } v s \text { within) }\end{array}$ & $75.0 \%$ & $82.9 \%$ & $\begin{array}{l}0.790 \\
(0.678- \\
0.901)\end{array}$ & $0.000 * \star \star$ & 7.532 & $0.035^{\star}$ \\
\hline $\begin{array}{l}\cdot \text { Tumor size }(\geq 3 \mathrm{~cm} \\
v s<3 \mathrm{~cm})\end{array}$ & $82.6 \%$ & $52.4 \%$ & $\begin{array}{l}0.675 \\
(0.558- \\
0.792)\end{array}$ & 0.010 ** & 3.148 & 0.141 \\
\hline $\begin{array}{l}\text { - Vascular } \\
\text { permeation (Yes vs } \\
\text { no) }\end{array}$ & $59.1 \%$ & $79.3 \%$ & $\begin{array}{l}0.692 \\
(0.559- \\
0.824)\end{array}$ & $0.006^{\star *}$ & 3.773 & 0.062 \\
\hline $\begin{array}{l}\text { - Pre-OT AFP level } \\
(\geq 400 \mathrm{ng} / \mathrm{ml} v s< \\
400 \mathrm{ng} / \mathrm{ml})\end{array}$ & $33.3 \%$ & $88.9 \%$ & $\begin{array}{l}0.612 \\
(0.474- \\
0.749)\end{array}$ & 0.097 & $\mathrm{~N} / \mathrm{A}$ & \\
\hline $\begin{array}{l}\text { - Graft weight to } \\
\text { recipient ESLV ( } \\
60 \% \text { vs }>60 \%)\end{array}$ & $75.0 \%$ & $37.8 \%$ & $\begin{array}{l}0.564 \\
(0.437- \\
0.691)\end{array}$ & 0.342 & $\mathrm{~N} / \mathrm{A}$ & \\
\hline $\begin{array}{l}\text { - Type of transplant } \\
\text { (LDLT vs DDLT) }\end{array}$ & $79.2 \%$ & $24.4 \%$ & $\begin{array}{l}0.518 \\
(0.387- \\
0.648)\end{array}$ & 0.792 & $\mathrm{~N} / \mathrm{A}$ & \\
\hline $\begin{array}{l}\cdot \text { Tumor number }(>3 \\
v s \leq 3)\end{array}$ & $34.8 \%$ & $89.0 \%$ & $\begin{array}{l}0.619 \\
(0.479- \\
0.759)\end{array}$ & 0.082 & $\mathrm{~N} / \mathrm{A}$ & \\
\hline $\begin{array}{l}\text { - Differentiation ( } \\
\text { Poor vs well) }\end{array}$ & $23.8 \%$ & $94.9 \%$ & $\begin{array}{l}0.593 \\
(0.446- \\
0.741)\end{array}$ & 0.190 & $\mathrm{~N} / \mathrm{A}$ & \\
\hline$\star, p<0.05 ; * *, p<0.01$. & & & & & & \\
\hline
\end{tabular}


Table 3

Univariate and multivariate Cox Regression analyses of disease-free survivals of HCC patients after liver transplantation

\begin{tabular}{|c|c|c|c|c|}
\hline \multirow[t]{3}{*}{ Factors } & \multicolumn{4}{|c|}{ Disease-free survival } \\
\hline & \multicolumn{2}{|c|}{ Univariate regression } & \multicolumn{2}{|c|}{ Multivariate regression } \\
\hline & $\mathrm{HR}(95 \% \mathrm{Cl})$ & $P$ value & $\mathrm{HR}(95 \% \mathrm{Cl})$ & $\begin{array}{l}P \\
\text { value }\end{array}$ \\
\hline - Plasma GSTA2 protein (High vs Low) & $\begin{array}{l}2.24(1.13- \\
4.45)\end{array}$ & $0.021^{\star}$ & $\begin{array}{l}1.75(0.81- \\
3.75)\end{array}$ & 0.154 \\
\hline - Sex (Male vs Female) & $\begin{array}{l}1.04(0.43- \\
2.51)\end{array}$ & 0.928 & & \\
\hline - Age $(<=55$ year $v s<55$ year $)$ & $\begin{array}{l}1.06(0.54- \\
2.08)\end{array}$ & 0.860 & & \\
\hline $\begin{array}{l}\text { - Serum AFP }(>400 \mathrm{ng} / \mathrm{ml} v s<= \\
400 \mathrm{ng} / \mathrm{ml})\end{array}$ & $\begin{array}{l}2.89(1.37- \\
6.07)\end{array}$ & $0.005^{\star \star}$ & $\begin{array}{l}1.73(0.70- \\
4.26)\end{array}$ & 0.234 \\
\hline - Tumor size $(>3 \mathrm{~cm} v s<=3 \mathrm{~cm})$ & $\begin{array}{l}1.96(0.95- \\
4.02)\end{array}$ & 0.068 & & \\
\hline - Tumor number $(>3 v s<=3)$ & $\begin{array}{l}2.00(0.09- \\
4.44)\end{array}$ & 0.088 & & \\
\hline - Vascular permeation (Yes vs No) & $\begin{array}{l}2.36(1.19- \\
4.68)\end{array}$ & $0.014^{\star}$ & $\begin{array}{l}1.246(0.54- \\
2.87)\end{array}$ & 0.606 \\
\hline - Differentiation (Poor vs Well) & $\begin{array}{l}3.08(1.26- \\
7.54)\end{array}$ & $0.013^{*}$ & $\begin{array}{l}1.90(0.73- \\
4.95)\end{array}$ & 0.191 \\
\hline - UCSF criteria (Beyond vs Within) & $\begin{array}{l}4.22(2.13- \\
8.37)\end{array}$ & $0.000 * \star \star$ & $\begin{array}{l}2.30(1.00- \\
5.31)\end{array}$ & 0.050 \\
\hline - Milan Criteria (Beyond vs Within) & $\begin{array}{l}3.09(1.53- \\
5.25)\end{array}$ & $0.002^{\star \star}$ & N/A & \\
\hline - Type of LT (DDLT vs LDLT) & $\begin{array}{l}1.30(0.61- \\
2.78)\end{array}$ & 0.500 & $\mathrm{~N} / \mathrm{A}$ & \\
\hline - Graft size $(>60 \%$ vs $<=60 \%)$ & $\begin{array}{l}0.75(0.38- \\
1.47)\end{array}$ & 0.402 & N/A & \\
\hline$*, p<0.05 ; * \star, p<0.01 ; * \star \star, P<0.001$ & & & & \\
\hline
\end{tabular}

\section{GSTA2 S112T polymorphism associated with HCC recurrence and survival after liver transplantation}

Analysis of the nucleotide sequence of GSTA2 transcript generated from RNA sequencing study revealed that 12 differential single nucleotide polymorphisms (SNPs) were identified between the comparison of the recurrence and non-recurrence recipients (Additional file 1, Table S3). There were 5 SNPs appeared in 
the coding sequence of GSTA2 transcript and in which 4 SNPs were non-synonymous (Additional file 1, Table S3). Sanger sequencing analysis of GSTA2 full length of GSTA2 cDNA (669 nucleotides encoding 222 amino acids) was conducted on the early phase liver biopsies of $60 \mathrm{HCC}$ recipients. Four SNPs were detected in the GSTA2 cDNA at the positions of 28(T > A), 329(C > T), 335(G >C ), and 629(A>C). These SNPs, either heterozygous or homozygous, were non-synonymous SNPs which changed the amino acid sequences the GSTA2 protein (Additional file 2, Fig.S1). Although the RNA sequencing analysis indicated a SNP allele at position of Chr6:52,622,717 (G > A, Additional file 1, Table S3) (or at nucleotide C29T), there was no SNP found from Sanger sequencing analysis at this position in all the samples. Instead, a SNP was found at T28A nucleotide position of the GSTA2 coding sequence (Table 4). Among all the detected SNPs, only the SNP at nucleotide position G335C (Fig. 2g) which results in residue S112T substitution was found to be significantly different between HCC recipients with and without HCC recurrence after liver transplantation ( $p=0.002$, Table 4$)$. None of the liver biopsies in recurrent recipients was detected with $\mathrm{G}$ allele at nucleotide position 335 of the GSTA2 coding sequence, while there were about $25 \%$ of non-recurrent recipients remained wild type $\mathrm{G}$ allele (Table 4 ). The percentage of heterogeneous SNP G335C in recipients with HCC recurrence was nearly 5-fold higher than recipients without HCC recurrence (Table 4). Moreover, G335C heterogeneous G/C alleles of GSTA2 coding sequence was significantly associated with poor overall and disease-free survival of HCC recipients (Fig. 2h). 
Table 4

Comparison of GSTA2 transcript SNPs between recipients with and without HCC recurrence after liver transplantation

\begin{tabular}{|c|c|c|c|c|c|c|}
\hline $\begin{array}{l}\text { Reference allele } \\
\text { (position in GSTA2 } \\
\text { coding sequence) }\end{array}$ & $\begin{array}{l}\text { Position of } \\
\text { amino acid } \\
\text { (codon } \\
\text { change) }\end{array}$ & $\begin{array}{l}\text { Codon } \\
\text { (Amino } \\
\text { Acid) }\end{array}$ & Genotype & $\begin{array}{l}\text { HCC } \\
\text { Recurrent } \\
\text { recipients } \\
(n=13)\end{array}$ & $\begin{array}{l}\text { Non-HCC } \\
\text { Recurrent } \\
\text { Recipients } \\
(n=47)\end{array}$ & $P$ value \\
\hline \multirow[t]{3}{*}{$\mathrm{T}(28)$} & $\begin{array}{l}10(\text { TCC } \\
\text { ACC })\end{array}$ & $\begin{array}{l}\text { TCC } \\
\text { (Ser) }\end{array}$ & $\begin{array}{l}\mathrm{T} / \mathrm{T} \\
\text { (Hom) }\end{array}$ & $\begin{array}{l}12 \\
(92.3 \%)\end{array}$ & $\begin{array}{l}46 \\
(97.9 \%)\end{array}$ & 0.389 \\
\hline & & $\begin{array}{l}\text { ACC } \\
\text { (Thr) }\end{array}$ & $\mathrm{T} / \mathrm{A}$ (Het) & 1 (7.7\%) & $1(2.1 \%)$ & \\
\hline & & $\begin{array}{l}\text { ACC } \\
\text { (Thr) }\end{array}$ & $\begin{array}{l}\text { A/A } \\
\text { (Hom) }\end{array}$ & $0(0 \%)$ & $0(0 \%)$ & \\
\hline \multirow[t]{3}{*}{ C (329) } & $\begin{array}{l}110(\mathrm{CCC} \diamond \\
\text { TCC) }\end{array}$ & $\begin{array}{l}\text { CCC } \\
\text { (Pro) }\end{array}$ & $\begin{array}{l}\mathrm{C} / \mathrm{C} \\
\text { (Hom) }\end{array}$ & $9(69.2 \%)$ & $\begin{array}{l}38 \\
(80.9 \%)\end{array}$ & 0.086 \\
\hline & & $\begin{array}{l}\text { TCC } \\
\text { (Ser) }\end{array}$ & $\mathrm{T} / \mathrm{C}$ (Het) & $3(23.1 \%)$ & $2(4.3 \%)$ & \\
\hline & & $\begin{array}{l}\text { TCC } \\
\text { (Ser) }\end{array}$ & $\begin{array}{l}\mathrm{T} / \mathrm{T} \\
\text { (Hom) }\end{array}$ & $1(7.7 \%)$ & $7(14.9 \%)$ & \\
\hline \multirow[t]{3}{*}{ G (335) } & $\begin{array}{l}112(A G T \\
\diamond A C T)\end{array}$ & $\begin{array}{l}\text { AGT } \\
\text { (Ser) }\end{array}$ & $\begin{array}{l}\text { G/G } \\
\text { (Hom) }\end{array}$ & $0(0 \%)$ & $\begin{array}{l}12 \\
(25.5 \%)\end{array}$ & $0.002^{\star *}$ \\
\hline & & $\begin{array}{l}\text { ACT } \\
\text { (Thr) }\end{array}$ & G/C (Het) & $6(46.2 \%)$ & $4(8.5 \%)$ & \\
\hline & & $\begin{array}{l}\text { ACT } \\
\text { (Thr) }\end{array}$ & $\begin{array}{l}\mathrm{C} / \mathrm{C} \\
\text { (Hom) }\end{array}$ & $7(53.8 \%)$ & $\begin{array}{l}32 \\
(68.1 \%)\end{array}$ & \\
\hline \multirow[t]{3}{*}{ A (629) } & $\begin{array}{l}210(G A G \diamond \\
\text { GCG) }\end{array}$ & $\begin{array}{l}\text { GAG } \\
\text { (Glu) }\end{array}$ & $\begin{array}{l}\text { A/A } \\
\text { (Hom) }\end{array}$ & $\begin{array}{l}11 \\
(84.6 \%)\end{array}$ & $\begin{array}{l}44 \\
(93.6 \%)\end{array}$ & 0.323 \\
\hline & & $\begin{array}{l}\text { GCG } \\
\text { (Ala) }\end{array}$ & A/C (Het) & $2(15.4 \%)$ & $2(4.3 \%)$ & \\
\hline & & $\begin{array}{l}\text { GCG } \\
\text { (Ala) }\end{array}$ & $\begin{array}{l}\mathrm{C} / \mathrm{C} \\
(\mathrm{Hom})\end{array}$ & $0(0 \%)$ & $1(2.1 \%)$ & \\
\hline
\end{tabular}

\section{The expression of GSTA2 was positively associated with aggressiveness of HCC}

The expression of GSTA2 mRNA in tumor or non-tumor tissues was significantly higher than in healthy donors (Fig. 3a). There was a significant upregulation of GSTA2 mRNA in the tumor tissues compared to the paired non-tumor issues of HCC patients (Fig. 3a). The expression level of GSTA2 protein was correlated with the GSTA2 mRNA (Fig. 3b). The expression of GSTA2 mRNA in HCC tumor tissues was significantly correlated with the size of the HCC tumor (Fig. 3c). HCC tumors detected with venous 
infiltration expressed significantly higher level of GSTA2 mRNA than those tumors without venous infiltration (Fig. 3d). The expression of GSTA2 mRNA in advanced HCC tissues was higher than the HCC tissues in early stage, but a statistical significance could not reach (Additional file 2, Fig.S2). The metastatic HCC cell line MHCC97L was found to exhibit the highest expression level of GSTA2 gene among different HCC cell lines, while the hepatoblastoma cell line, HepG2, was detected with the lowest levels of GSTA2 mRNA and protein (Additional file 2, Fig.S3). In addition, the expression of GSTA2 mRNA was examined in in vivo rat liver tumors which were obtained from our previous study(9), the more aggressive liver tumors have been established in small size liver under ischemic-reperfusion (I/R) treatment compared to the generated liver tumors in normal liver without I/R treatment. Interestingly, the expression of GSTA2 mRNA in the more aggressive rat liver tumors was significantly higher than in the less aggressive tumors (Fig. 3e).

\section{Overexpression of GSTA2 promoted HCC growth and aggression}

Established GSTA2-overexpressing stable HCC cells were validated to overexpress GSTA2 mRNA and protein compared to the HCC cells infected with control virus (Additional file 2, Fig.S4). The GSTA2overexpressing HCC cells significantly higher proliferation rate than the control cells (Fig. 3f). Administration of human recombinant GSTA2 protein could significantly speed up the growth rate of the HCC cells (Fig. 3f). The colony-forming ability of the HCC cells was significantly enhanced by either endogenous overexpression of GSTA2 gene or exogenous addition of recombinant GSTA2 protein (Fig. 3g). The invasion ability (Fig. 3h) of the HCC cells was enhanced when upregulation of GSTA2 either by endogenous or exogenous means. Increased level of GSTA2 did not enhance the migration ability of the HCC cells (Fig. 3i). Further investigation on the expression level of a panel of epithelial-mesenchymal transition (EMT)-associated protein revealed that increased level of GSTA2 could upregulate the expression of EMT-associated proteins such as N-cadherin, vimentin. claudin, beta-catenin and snail (Fig. 3j).

\section{Suppression of GSTA2 could inhibit the growth and metastasis of HCC cells.}

Among our tested HCC cell lines, the metastatic HCC cell line, MHCC97L, was detected to have the highest level of GSTA2 mRNA and protein (Additional file 2, Fig.S3). We further investigated whether targeted inhibition of GSTA2 can achieve anti-tumor and anti-metastasis on this malignant HCC cells. The expression of GSTA2 mRNA in GSTA2-suppressing cells was significantly suppressed by more than 5 folds (Fig. 4a). The level of GSTA2 protein was also notably suppressed in the GSTA2-suppressing cells (Fig. 4a). Suppression of GSTA2 could significantly reduce the proliferation rate of the HCC cells from day 1 to day 3 (Fig. 4b). Importantly, suppression of GSTA2 expression significantly reduced the invasion ability of HCC cells (Fig. 4c). Agreed with the in vitro finding, the size of the subcutaneous in GSTA2suppressing cells after 4 weeks was significantly smaller than the control cells (Fig. 4d). Importantly, no metastatic tumor was detected in the lung tissue in the GSTA2-suppressing cells, while 3 out of 8 nude mice (37.5\%) were found to develop metastatic tumor in the lung in the control group (Fig. 4e). 


\section{The protective role of GSTA2 for HCCs against high oxidative stress-induced cell death}

The concentration of GSTA2 protein was found to be surged at early phase after liver transplantation and was significantly correlated with the plasma ROS level (Table 1). GSTA2 functions as an anti-oxidant. Hence, we conducted series of in vitro experiments to investigate the possible function of exogenously and endogenously increased level of GSTA2 protein on normal hepatocytes and HCC cells under a high ROS condition which happens during early phase after liver transplantation. We found that the normal hepatocyte cell line would elevate intracellular ROS level in responding to the increased concentrations of $\mathrm{H}_{2} \mathrm{O}_{2}$ (ROS assay, Fig. 5a). High ROS level caused a harmful effect on normal hepatocytes, leading to a reduction of proliferation rate (MTT assay, Fig. 5a). Administration of human recombinant GSTA2 protein could help the normal hepatocytes to compensate the $\mathrm{H}_{2} \mathrm{O}_{2}$-induced upregulation of ROS and reduce the anti-proliferative effect under a high ROS condition (ROS assay, Fig. 5a). Meanwhile, administration of exogenous human recombinant GSTA2 protein or forced overexpression of GSTA2 gene in HCC cells could contribute a compensation effect on $\mathrm{H}_{2} \mathrm{O}_{2}$-induced ROS elevation (ROS assay Fig. 5b). HCC cells with either increased level of exogenous or endogenous GSTA2 exhibited a significantly higher proliferation rate than the control cells under a high-ROS condition (MTT assay, Fig. 5b). Apoptosis assay revealed that upregulation of GSTA2 expression, either by exogenous or endogenous means, could protect the $\mathrm{HCC}$ cells against high $\mathrm{H}_{2} \mathrm{O}_{2}$-induced apoptosis (Fig. $5 \mathrm{c}$ ). In addition, suppression of GSTA2 expression in the metastatic $\mathrm{HCC}$ cells further intensified the effect of $\mathrm{H}_{2} \mathrm{O}_{2}$, leading to a significantly higher intracellular ROS level and a significantly slower proliferation rate compared to the control cells (Fig. 5d).

\section{GSTA2 regulated ROS metabolism of HCC}

Two important ROS-mediating signaling pathways were characterized in GSTA2-overexpressing and GSTA2-suppressing HCC cells. Overexpression of GSTA2 in HCC cells could suppress its ROS-mediated activation of JNK pathway, while suppression of GSTA2 could upsurge the activation of JNK pathway of HCC cells under an increased ROS condition (Fig. 5e). Overexpression of GSTA2 in HCC cells enhanced the activation of AKT pathway under ROS-stimulation, while suppression of GSTA2 inhibited the activation of AKT pathway in HCC cells (Fig. 5e). The effect of GSTA2 on the expression level of 84 ROSassociated genes under $\mathrm{H}_{2} \mathrm{O}_{2}$ environment was studied by RT2 PCR array analysis. By comparing the expression level between MHCC97L-shGSTA2 and MHCC97L-control cells, there were 5 up-regulated (ALB, TPO, GPX5, NCF2, and APOE) and 10 down-regulated (NCF1, SOD3, MT3, MBL2, CYBB, TTN, FTH1, SPINK1, PTGS1, PTGS2) genes related to oxidative stress were identified in MHCC97L-shGSTA2 cells under $\mathrm{H}_{2} \mathrm{O}_{2}$ condition (Fig. $5 f$ ). Among them, eight of them are involved in ROS metabolism including TPO, SOD3, NCF1, NCF2, APOE, FTH1, GPX5 and MBL2. The correlation analysis of the expression of GSTA2 and the identified ROS-associated genes using the LIHC database in the GEPIA web server revealed that the expression level of GSTA2 was significantly correlated with ALB, TPO, APOE, MBL2 and FTH1 in the tumor tissues (Additional file 2, Fig.S5). 


\section{Discussion}

HCC recurrence after liver transplantation remains a significant cause of poor survival in HCC recipients. In fact, expansion of donor pools in solving the problem of organ donor shortage, for instances using partial living donor grafts and marginal grafts, potentially increases the risk of tumor recurrence after liver transplantation $(3,33)$. Despite of employing selection strategies to minimize the potential high-risk HCC patients, deciphering its underlying risk factors becomes a critical task in developing effective strategies to predict and prevent $\mathrm{HCC}$ recurrence $(34,35)$. Increasing evidences from clinical and experimental research have demonstrated a positive correlation between post-transplant early phase I/R injury and late phase tumor recurrence $(7,36,37)$. Studies have pointed out that elevated systemic and regional inflammatory responses during the early phase can increase the likelihood of late phase tumor recurrence $(7,10,37,38)$. Studies have also demonstrated that reduction of I/R injury is a conceivable strategy to diminish the risk of late phase tumor recurrence $(37,39)$. Still, there are many uncovered aspects of why and how does early phase I/R injury affect the happening of HCC recurrence after liver transplantation. This study aimed to identify novel HCC-recurrence-associated molecular targets from post-LT early phase, that could lead to development of novel early predictive and preventive strategies to combat HCC recurrence after liver transplantation.

In the present study, by profiling the transcriptomic of the liver biopsies obtained at the early phase after liver transplantation and comparing the difference between HCC recipients with and without late phase HCC recurrence, a panel of differential genes were identified. GSTA2 gene was identified to be the most upregulated gene in $\mathrm{HCC}$ recipients who developed recurred $\mathrm{HCC}$ at late phase after liver transplantation compared to HCC recipients without developing HCC recurrence. The expression level of hepatic GSTA2 gene was significantly correlated with the expression level of genes associated with hepatic injury including TNF $a$ and TGF $b$ genes, suggesting GSTA2 may be a hepatic injury-responding gene during early

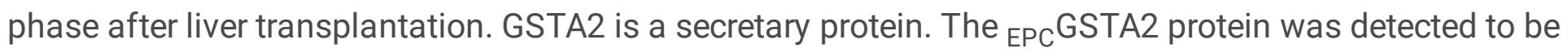
significantly upregulated after reperfusion of the liver. There was no significantly association between EPC GSTA2 protein and pre-transplantation clinicopathological factors, indicating a systemic upregulation of GSTA2 resulted from I/R injury during early phase of liver transplantation. Study in mice model reported that GSTA2 is one of the upregulated gene in responding to sulfasalazine-induced liver injury (40). Our data provided several evidences to demonstrate a close relationship of EPCGSTA2 with hepatic and systemic injury at early phase after liver transplantation including warm ischemic time, post-

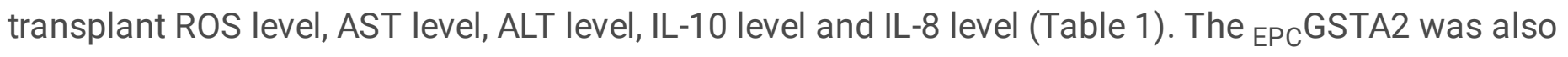
significantly correlated with our previously identified microRNA miR-1246 (Table 1) whose level at early phase is also significantly associated with hepatic injury after liver transplantation (13). Serum aminotransferases including ALT and AST are commonly recognized markers for diagnosis and monitoring of liver injury, however the indication for liver injury by aminotransferases cannot fulfil the purpose of different clinical applications (41). New biomarkers such as microRNAs have been emerged to compensate the indications of aminotransferases on liver injury under surgical operations including liver 
transplantation (42). Therefore, our present findings indicated that GSTA2 is a novel biomarker to indicate hepatic and systemic injury at early phase of liver transplantation.

We further determined that this ${ }_{\text {EPC }}$ GSTA2 protein exhibited significant correlation with late phase HCC recurrence of $\mathrm{HCC}$ recipients after liver transplantation. The accuracy of ${ }_{\text {EPC }}$ GSTA2 protein in predicting

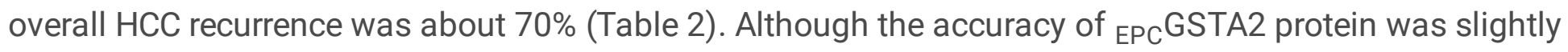
lower than Milan criteria $(A U C=0.752)$ and UCSF criteria $(A U C=0.790)$, the specificity of ${ }_{E P C} G S T A 2$ in predicting HCC recurrence was higher than these criteria. Moreover, EPCGSTA2 protein was found to be an independent predictor with USCF in predicting HCC recurrence after liver transplantation (Table 2), demonstrating the independent risks from pre-transplant and post-transplant factors in affecting HCC recurrence after liver transplantation. Apart from predicting $\mathrm{HCC}$ recurrence, high level of ${ }_{\text {EPC GSTA2 }}$ protein could significantly predict disease-free survival of HCC recipients after liver transplantation (Fig. 2e and Table 3). Multivariate Cox Regression analysis of the significant predictors of disease-free survival showed that there was no a significantly independent predictor defined (Table 3), suggesting that these predictors dependently influenced the disease-free survival of HCC recipients. These above findings agreed with our previous study that early phase injury-induced molecules play influential roles in late phase HCC recurrence after liver transplantation (14). Altogether, our results indicated that ${ }_{\text {EPC GSTA2 }}$ protein is a potential non-invasive biomarker not only for indication of post-LT early phase hepatic and systemic injury but also for prediction of late phase $\mathrm{HCC}$ recurrence and survival of HCC recipients. It has been pointed out that a single biomarker is difficult to achieve perfect prediction on HCC recurrence after liver transplantation due to highly diverse tumor behaviours among patients (5). Further investigation on integrating GSTA2 with clinicopathological parameters is necessary for constructing effective prediction models on HCC recurrence after liver transplantation.

RNA sequencing analysis indicated several nucleotide polymorphisms within the GSTA2 transcript of the liver from early phase between recurrent and non-recurrent recipients. Sanger sequencing study of GSTA2 coding nucleotide sequence illustrated that the frequency of nucleotide G335C SNP of GSTA2 coding sequencing, a GSTA2 protein residue S112T substitution, was significantly different between HCCrecurrence recipients and non-HCC-recurrence recipients (Table 4). The percentage of heterozygous G/C alleles of G335C SNP in recurrent group was 5 -fold greater than in non-recurrent group, indicating this heterozygous SNP to be a potential risk factor of post-transplantation HCC recurrence. In addition to the association with HCC recurrence, GSTA2 heterozygous G/C alleles of G335C SNP in the donor livers was significantly associated with the poorest overall and disease-free survival (Fig. 2h). Unlike our finding, the GSTA2 S112T serine homozygosity has been reported to be an independent prognostic factor of poor survival in acute leukemia patients received allogenic stem cell transplantation (43). We postulated that the effect of GSTA2 S112T polymorphism is dependent on different clinical situations. Owing that GSTA2 S112T polymorphism might affect the survival outcome of different diseases, assessment on GSTA2 polymorphism in the liver tissues of the donors may provide important clinical information for stratification of high-risk recipients for closely monitoring after liver transplantation. In addition, studies has demonstrated that the S112T change does not cause the change of protein structure and enzymatic

Page 21/44 
activity of GSTA2 protein, but affects the level and thermostability of GSTA2 protein in the liver (44-46). A study has also suggested that GSTA2 S112T polymorphism affects bilirubin metabolism after busulfan-conditioned allogenic transplants (43). However, we did not detect a significant correlation between GSTA2 S112T polymorphism and total bilirubin in HCC recipients after liver transplantation. We postulated that bilirubin metabolism after liver transplantation may be influenced by multifactorial factors rather than a single factor.

To delineate the possible reasons of why upregulation of GSTA2 would lead to an increased risk of HCC recurrence after liver transplantation, we further investigated the expression level and functions of GSTA2 in HCC. We found that the expression level of GSTA2 mRNA in tumor tissues of HCC patients was significantly higher than the matched non-tumor tissues and the healthy donors, indicating that GSTA2 is commonly upregulated in human HCCs. The expression level of GSTA2 mRNA was significantly correlated with tumor size and presence of venous infiltration, suggesting that the expression level of GSTA2 is positively correlated with HCC malignancy. The metastatic HCC cell line expressed the highest level of GSTA2 mRNA and protein over other non-metastatic HCC cell lines, implying that GSTA2 may play important role in HCC metastasis. In addition, by analyzing the HCC tissues developed from rat liver transplantation model, we found that the expression level of GSTA2 mRNA in the more aggressive tumor tissues was significantly higher than in the less aggressive tumor tissues. So far, the expression patterns of GSTA2 has not yet to determine. Our study revealed for the first time that GSTA2 is commonly upregulated in human HCCs and positively correlated to HCC malignancy.

Functionally, we found that overexpression of endogenous GSTA2 in HCC cells could promote their proliferation rate, migration rate and invasion ability. Interestingly, administration of human recombinant GSTA2 protein could also exhibit the similar effect on HCC cells. The increased level of either endogenous or exogenous GSTA2 protein could activate the expression of several epithelial-mesenchymal-transition (EMT) - promoting proteins including $\mathrm{N}$-cadherin, vimentin and claudin-1. Suppression of GSTA2 in the metastatic HCC cell line could inhibit its in vitro and in vivo metastatic ability. A recent study has demonstrated that targeted inhibition of glutathione and thioredoxin antioxidant pathways can synergistically kill cancer cells, suggesting that antioxidant systems are important for the initiation and progression of cancer cells (47). Therefore, our results indicated that GSTA2 plays essential role in metastasis of HCCs and targeted inhibition of GST2 may be a potential therapeutic method for treatment of HCC.

GSTA2 is mainly produced from the liver and functions in detoxifying electrophilic compounds such as the products of oxidative stress (19). Our results showed that the expression of hepatic GSTA2 mRNA at early phase after liver transplantation was significantly correlated with the expression level of several ROS-regulatory genes such as NRF2, SOD3, GPX2 and GPX3. The level of early phase circulating GSTA2 (EPCGSTA2) protein was also significantly correlated with the ROS level at early phase after liver transplantation. These results indicated a close relationship between GSTA2 and the hepatic and systemic ROS metabolism at the early phase after liver transplantation. Further experimental results demonstrated that elevated level of exogenous GSTA2 protein could help the normal liver cells and HCC 
cells to compensate their ROS level in responding to $\mathrm{H}_{2} \mathrm{O}_{2}$-induced oxidative stress, that subsequently protected them against the $\mathrm{H}_{2} \mathrm{O}_{2}$-induced apoptosis and death. Meanwhile, overexpression of GSTA2 in $\mathrm{HCC}$ cells could also provide protective effect for HCC cells against high ROS-induced cell death. These above findings agreed with other study that GSTA2 can contribute a protective effect on cells against ROS cytotoxicity (19). Moreover, our experiments demonstrated that suppression of GSTA2 expression in $\mathrm{HCC}$ cells could lead to a further elevated level of ROS in $\mathrm{HCC}$ cells under high $\mathrm{H}_{2} \mathrm{O}_{2}$ condition, increasing the numbers of died cells. We further characterized that alteration of the expression of GSTA2 could influence the activation of ROS-associated signalling pathways such as JNK and AKT pathways in responding to the change of ROS environment. In addition, downregulation of GSTA2 expression in HCC cells led to alteration of the expression of several ROS-associated genes under the $\mathrm{H}_{2} \mathrm{O}_{2}$ condition, suggesting that GSTA2 is important in maintaining the ROS metabolism of HCC cells in responding to the changes of ROS condition. Cancer cells exhibit a phenomenon of a relatively high intracellular level of oxidative stress because of aberrant metabolism for abnormal proliferation and progression $(48,49)$. However, high ROS level is harmful for cancer cells, making the role of ROS in cancer remain controversial $(17,18)$. Several lines of evidences have indicated that cancer cells establish counteracting effect to high ROS by increasing the level antioxidant enzymes to modulate the ROS level to be favorable for themselves $(17,50,51)$. Therefore, our results indicated that upregulation of GSTA2 at early phase provides protective advantages for HCC cells to survival against high ROS-induced damage during early phase after liver transplantation and subsequently increases the likelihood of HCC recurrence.

Altogether, our results demonstrated the possible mechanism of GSTA2 in HCC recurrence after liver transplantation (Fig. 6): Elevated early phase hepatic I/R injury after liver transplantation contributes to high ROS environment which would cause harmful effects on HCC cells. GSTA2 is induced by I/R injury and upregulated in the liver and in the circulation subsequently provides protective advantages for HCC cells to survival against high ROS-induced damage. When ROS level decreased along with the recovery of hepatic I/R injury during later time point of liver transplantation, GSTA2 provides anti-oxidative benefit for HCC cells to initiate the growth and progression in an earlier period. Therefore, our study suggested the possible mechanism that upregulation of GSTA2 at early phase after liver transplantation increases the risk of HCC recurrence through maintaining a favorable ROS environment for HCC cells to survival and progression.

\section{Conclusions}

In conclusion, augmentation of GSTA2 at early phase after liver transplantation increases the risk of late phase $\mathrm{HCC}$ recurrence after liver transplantation through regulating the ROS metabolism. These findings should provide important information to understand the mechanism in bridging early phase hepatic injury with late phase HCC recurrence after liver transplantation.

\section{Abbreviations}


AFP, alpha fetoprotein; DDLT, deceased donor liver transplantation; EMT, epithelial-mesenchymaltransition; EPCGSTA2, early phase circulating GSTA2; GSTA2, glutathione S-transferase A2; HCC, hepatocellular carcinoma; I/R, Ischemia-reperfusion; LT, liver transplantation; LDLT, living donor liver transplantatation; ROC, Receiver Operating Characteristic; ROS, reactive oxygen species; RT-PCR, reverse transcriptase polymerase chain reaction; shRNA, short hairpin RNA; SNP, single nucleotide polymorphism; TUNEL, Terminal deoxynucleotidyl transferase dUTP nick end labeling.

\section{Declarations}

\section{Ethics approval and consent to participate}

All clinical samples were obtained from patients with signed consent and the collection of the samples by the Surgical Tissue Bank was approved by the ethics committee of Institutional Review Board of the University of Hong Kong/Hospital Authority Hong Kong West Cluster (HKU/HA HKW IRB, Ref. UW 05-359 T/1022). Animal experiment was approved by Animal (Control of Experiments) Ordinance Chapter 340, the Department of Health, Hong Kong Special Administrative Region (Ref.: (18-127) in DH/SHS/8/2/3 Pt. 12).

\section{Consent for publication}

Not applicable

\section{Availability of data and materials}

All the other data supporting the findings of this study are available within the article and its additional files.

\section{Competing interests}

The authors declare no conflict of interest.

\section{Funding}

This study was supported by General Research Fund $(17101017,17122517$ \& 17159616) and the Themebased Research Scheme (T12-703/19R) and of the Research Grants Council, the Seed Funding Programme (201910159141, 201811159027, 201711159018 and 201611159111) of the University of Hong Kong.

\section{Authors' contributions}

NKT and MK designed the study, organized the study, analyzed and interpreted study data and wrote the manuscript. YOW, LH, LJ, LYF, LMH, ZJY, PL, YXX, ZWY, QWQ, SHC and LMK performed the experiments, analyzed the data and helped to draft the output and critically reviewed the manuscript; CML interpreted the data and critically reviewed the manuscript. 
Acknowledgements

We thank the staff in the Surgical Tissue Bank, Department of Surgery, HKU, for preparing the clinical materials.

\section{References}

1. Yang JD, Hainaut P, Gores GJ, Amadou A, Plymoth A, Roberts LR. A global view of hepatocellular carcinoma: trends, risk, prevention and management. Nat Rev Gastroenterol Hepatol. 2019;16(10):589-604.

2. Maggs JR, Suddle AR, Aluvihare V, Heneghan MA. Systematic review: the role of liver transplantation in the management of hepatocellular carcinoma. Aliment Pharmacol Ther. 2012;35(10):1113-34.

3. Kulik LM, Fisher RA, Rodrigo DR, Brown RS, Jr., Freise CE, Shaked A, et al. Outcomes of living and deceased donor liver transplant recipients with hepatocellular carcinoma: results of the A2ALL cohort. American journal of transplantation : official journal of the American Society of Transplantation and the American Society of Transplant Surgeons. 2012;12(11):2997-3007.

4. Chan SC, Cheung TT, Chan AC, Chok KS, Sharr WW, Fung JY, et al. New insights after the first 1000 liver transplantations at The University of Hong Kong. Asian J Surg. 2015.

5. Citores MJ, Lucena JL, de la Fuente S, Cuervas-Mons V. Serum biomarkers and risk of hepatocellular carcinoma recurrence after liver transplantation. World J Hepatol. 2019;11(1):50-64.

6. Yang $F$, Zhang $Y$, Ren $H$, Wang J, Shang L, Liu Y, et al. Ischemia reperfusion injury promotes recurrence of hepatocellular carcinoma in fatty liver via ALOX12-12HETE-GPR31 signaling axis. $J$ Exp Clin Cancer Res. 2019;38(1):489.

7. Grat M, Krawczyk M, Wronka KM, Stypulkowski J, Lewandowski Z, Wasilewicz M, et al. Ischemiareperfusion injury and the risk of hepatocellular carcinoma recurrence after deceased donor liver transplantation. Sci Rep. 2018;8(1):8935.

8. Orci LA, Lacotte S, Delaune V, Slits F, Oldani G, Lazarevic V, et al. Effects of the gut-liver axis on ischaemia-mediated hepatocellular carcinoma recurrence in the mouse liver. Journal of hepatology. 2018;68(5):978-85.

9. Man K, Ng KT, Lo CM, Ho JW, Sun BS, Sun CK, et al. Ischemia-reperfusion of small liver remnant promotes liver tumor growth and metastases-Activation of cell invasion and migration pathways. Liver transplantation : official publication of the American Association for the Study of Liver Diseases and the International Liver Transplantation Society. 2007;13(12):1669-77.

10. Man K, Lo CM, Xiao JW, Ng KT, Sun BS, Ng IO, et al. The significance of acute phase small-for-size graft injury on tumor growth and invasiveness after liver transplantation. Ann Surg. 2008;247(6):1049-57.

11. Li CX, Ling CC, Shao Y, Xu A, Li XC, Ng KT, et al. CXCL10/CXCR3 signaling mobilized-regulatory T cells promote liver tumor recurrence after transplantation. Journal of hepatology. 2016. 
12. Ling CC, Ng KT, Shao Y, Geng W, Xiao JW, Liu H, et al. Post-transplant endothelial progenitor cell mobilization via CXCL10/CXCR3 signaling promotes liver tumor growth. Journal of hepatology. 2014;60(1):103-9.

13. Ng KT, Lo CM, Wong N, Li CX, Qi X, Liu XB, et al. Early-phase circulating miRNAs predict tumor recurrence and survival of hepatocellular carcinoma patients after liver transplantation. Oncotarget. 2016;7(15):19824-39.

14. Lee NP, Wu H, Ng KTP, Luo R, Lam TW, Lo CM, et al. Transcriptome Analysis of Acute Phase Liver Graft Injury in Liver Transplantation. Biomedicines. 2018;6(2).

15. Casillas-Ramirez A, Mosbah IB, Ramalho F, Rosello-Catafau J, Peralta C. Past and future approaches to ischemia-reperfusion lesion associated with liver transplantation. Life sciences. 2006;79(20):188194.

16. Elias-Miro M, Jimenez-Castro MB, Rodes J, Peralta C. Current knowledge on oxidative stress in hepatic ischemia/reperfusion. Free radical research. 2013;47(8):555-68.

17. Gorrini C, Harris IS, Mak TW. Modulation of oxidative stress as an anticancer strategy. Nature reviews Drug discovery. 2013;12(12):931-47.

18. Tong L, Chuang CC, Wu S, Zuo L. Reactive oxygen species in redox cancer therapy. Cancer letters. 2015;367(1):18-25.

19. Hayes JD, Flanagan JU, Jowsey IR. Glutathione transferases. Annual review of pharmacology and toxicology. 2005;45:51-88.

20. Xie J, Shults K, Flye L, Jiang F, Head DR, Briggs RC. Overexpression of GSTA2 protects against cell cycle arrest and apoptosis induced by the DNA inter-strand crosslinking nitrogen mustard, mechlorethamine. Journal of cellular biochemistry. 2005;95(2):339-51.

21. Maekawa K, Hamaguchi T, Saito Y, Tatewaki N, Kurose K, Kaniwa N, et al. Genetic variation and haplotype structures of the glutathione S-transferase genes GSTA1 and GSTA2 in Japanese colorectal cancer patients. Drug metabolism and pharmacokinetics. 2011;26(6):646-58.

22. Silva SN, Azevedo AP, Teixeira V, Pina JE, Rueff J, Gaspar JF. The role of GSTA2 polymorphisms and haplotypes in breast cancer susceptibility: a case-control study in the Portuguese population. Oncology reports. 2009;22(3):593-8.

23. Gemignani F, Landi S, Szeszenia-Dabrowska N, Zaridze D, Lissowska J, Rudnai P, et al. Development of lung cancer before the age of 50 : the role of xenobiotic metabolizing genes. Carcinogenesis. 2007;28(6):1287-93.

24. Lee JY, Han CY, Yang JW, Smith C, Kim SK, Lee EY, et al. Induction of glutathione transferase in insulin-like growth factor type I receptor-overexpressed hepatoma cells. Molecular pharmacology. 2007;72(4):1082-93.

25. Ng KT, Xu A, Cheng Q, Guo DY, Lim ZX, Sun CK, et al. Clinical relevance and therapeutic potential of angiopoietin-like protein 4 in hepatocellular carcinoma. Molecular cancer. 2014;13(1):196.

26. Ng KT, Qi X, Kong KL, Cheung BY, Lo CM, Poon RT, et al. Overexpression of matrix metalloproteinase12 (MMP-12) correlates with poor prognosis of hepatocellular carcinoma. Eur J Cancer. 2011. 
27. Li Y, Tang ZY, Ye SL, Liu YK, Chen J, Xue Q, et al. Establishment of cell clones with different metastatic potential from the metastatic hepatocellular carcinoma cell line MHCC97. World $\mathrm{J}$ Gastroenterol. 2001;7(5):630-6.

28. Ng KT, Lee TK, Cheng Q, Wo JY, Sun CK, Guo DY, et al. Suppression of tumorigenesis and metastasis of hepatocellular carcinoma by shRNA interference targeting on homeoprotein Six1. Int J Cancer. 2010;127(4):859-72.

29. Ng KT, Lo CM, Guo DY, Qi X, Li CX, Geng W, et al. Identification of transmembrane protein 98 as a novel chemoresistance-conferring gene in hepatocellular carcinoma. Molecular cancer therapeutics. 2014;13(5):1285-97.

30. Ng KT, Yeung OW, Liu J, Li CX, Liu H, Liu XB, et al. Clinical significance and functional role of transmembrane protein 47 (TMEM47) in chemoresistance of hepatocellular carcinoma. Int J Oncol. 2020;57(4):956-66.

31. Livak KJ, Schmittgen TD. Analysis of relative gene expression data using real-time quantitative PCR and the 2(-Delta Delta C(T)) Method. Methods. 2001;25(4):402-8.

32. Tang Z, Li C, Kang B, Gao G, Li C, Zhang Z. GEPIA: a web server for cancer and normal gene expression profiling and interactive analyses. Nucleic Acids Res. 2017;45(W1):W98-W102.

33. Lo CM, Fan ST, Liu CL, Chan SC, Ng IO, Wong J. Living donor versus deceased donor liver transplantation for early irresectable hepatocellular carcinoma. Br J Surg. 2007;94(1):78-86.

34. Toso C, Mentha G, Majno P. Liver transplantation for hepatocellular carcinoma: five steps to prevent recurrence. American journal of transplantation : official journal of the American Society of Transplantation and the American Society of Transplant Surgeons. 2011;11(10):2031-5.

35. Kim B, Kahn J, Terrault NA. Liver transplantation as therapy for hepatocellular carcinoma. Liver Int. 2020;40 Suppl 1:116-21.

36. Li CX, Man K, Lo CM. The Impact of Liver Graft Injury on Cancer Recurrence Posttransplantation. Transplantation. 2017;101(11):2665-70.

37. Man K. Recurrent malignancy: Are we pushing the envelope? Liver transplantation : official publication of the American Association for the Study of Liver Diseases and the International Liver Transplantation Society. 2017;23(S1):S81-S4.

38. Man K, Shih KC, Ng KT, Xiao JW, Guo DY, Sun CK, et al. Molecular signature linked to acute phase injury and tumor invasiveness in small-for-size liver grafts. Ann Surg. 2010;251(6):1154-61.

39. Oldani G, Crowe LA, Orci LA, Slits F, Rubbia-Brandt L, de Vito C, et al. Pre-retrieval reperfusion decreases cancer recurrence after rat ischemic liver graft transplantation. Journal of hepatology. 2014;61(2):278-85.

40. Li YC, Shen JD, Lu SF, Zhu LL, Wang BY, Bai M, et al. Transcriptomic analysis reveals the mechanism of sulfasalazine-induced liver injury in mice. Toxicol Lett. 2020;321:12-20.

41. McGill MR. The past and present of serum aminotransferases and the future of liver injury biomarkers. EXCLI J. 2016;15:817-28. 
42. Christou CD, Tsoulfas G. The role of microRNA in hepatic ischemia/reperfusion injury. Microrna. 2020.

43. Bonifazi F, Storci G, Bandini G, Marasco E, Dan E, Zani E, et al. Glutathione transferase-A2 S112T polymorphism predicts survival, transplant-related mortality, busulfan and bilirubin blood levels after allogeneic stem cell transplantation. Haematologica. 2014;99(1):172-9.

44. Tetlow N, Board PG. Functional polymorphism of human glutathione transferase A2. Pharmacogenetics. 2004;14(2):111-6.

45. Ning B, Wang C, Morel F, Nowell S, Ratnasinghe DL, Carter W, et al. Human glutathione S-transferase A2 polymorphisms: variant expression, distribution in prostate cancer cases/controls and a novel form. Pharmacogenetics. 2004;14(1):35-44.

46. Coles BF, Morel F, Rauch C, Huber WW, Yang M, Teitel CH, et al. Effect of polymorphism in the human glutathione S-transferase A1 promoter on hepatic GSTA1 and GSTA2 expression. Pharmacogenetics. 2001;11(8):663-9.

47. Harris IS, Treloar AE, Inoue S, Sasaki M, Gorrini C, Lee KC, et al. Glutathione and thioredoxin antioxidant pathways synergize to drive cancer initiation and progression. Cancer cell. 2015;27(2):211-22.

48. Cairns RA, Harris IS, Mak TW. Regulation of cancer cell metabolism. Nature reviews Cancer. 2011;11(2):85-95.

49. Liou GY, Storz P. Reactive oxygen species in cancer. Free radical research. 2010;44(5):479-96.

50. Diehn M, Cho RW, Lobo NA, Kalisky T, Dorie MJ, Kulp AN, et al. Association of reactive oxygen species levels and radioresistance in cancer stem cells. Nature. 2009;458(7239):780-3.

51. Kim HM, Haraguchi N, Ishii H, Ohkuma M, Okano M, Mimori K, et al. Increased CD13 expression reduces reactive oxygen species, promoting survival of liver cancer stem cells via an epithelialmesenchymal transition-like phenomenon. Annals of surgical oncology. 2012;19 Suppl 3:S539-48.

\section{Figures}


A

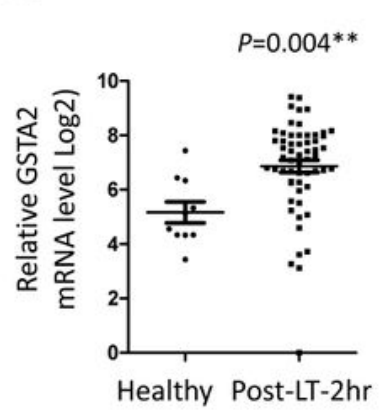

B

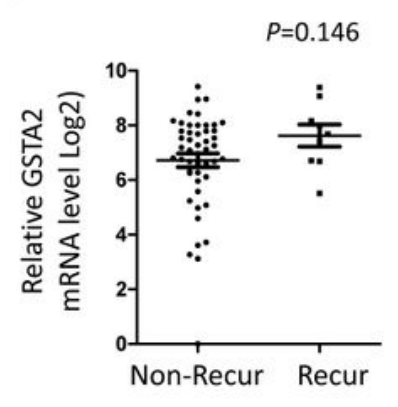

C

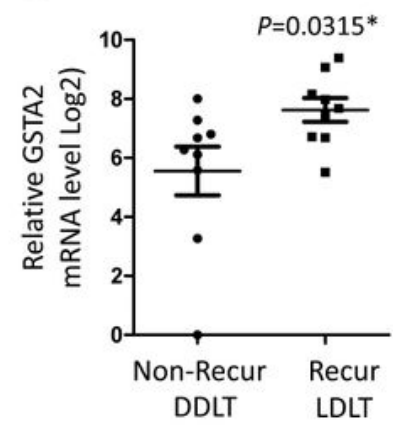

D

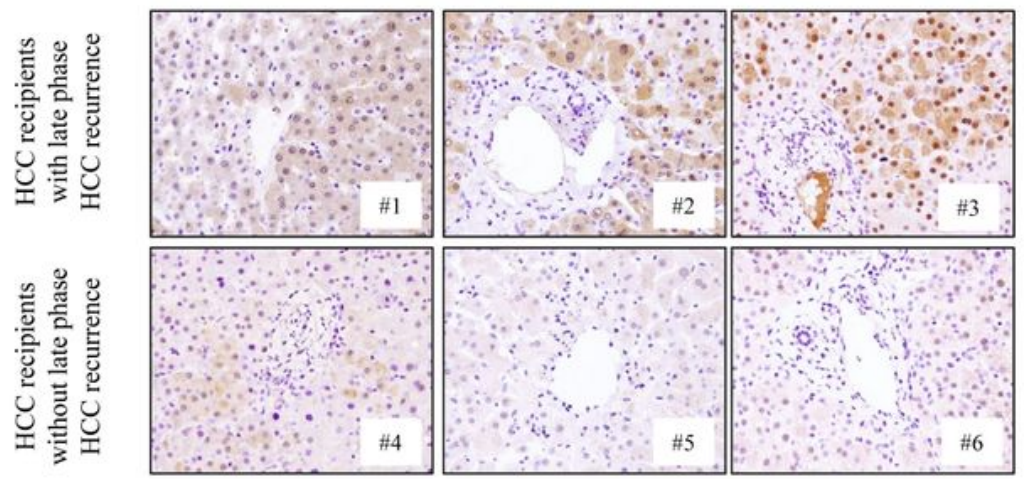

E
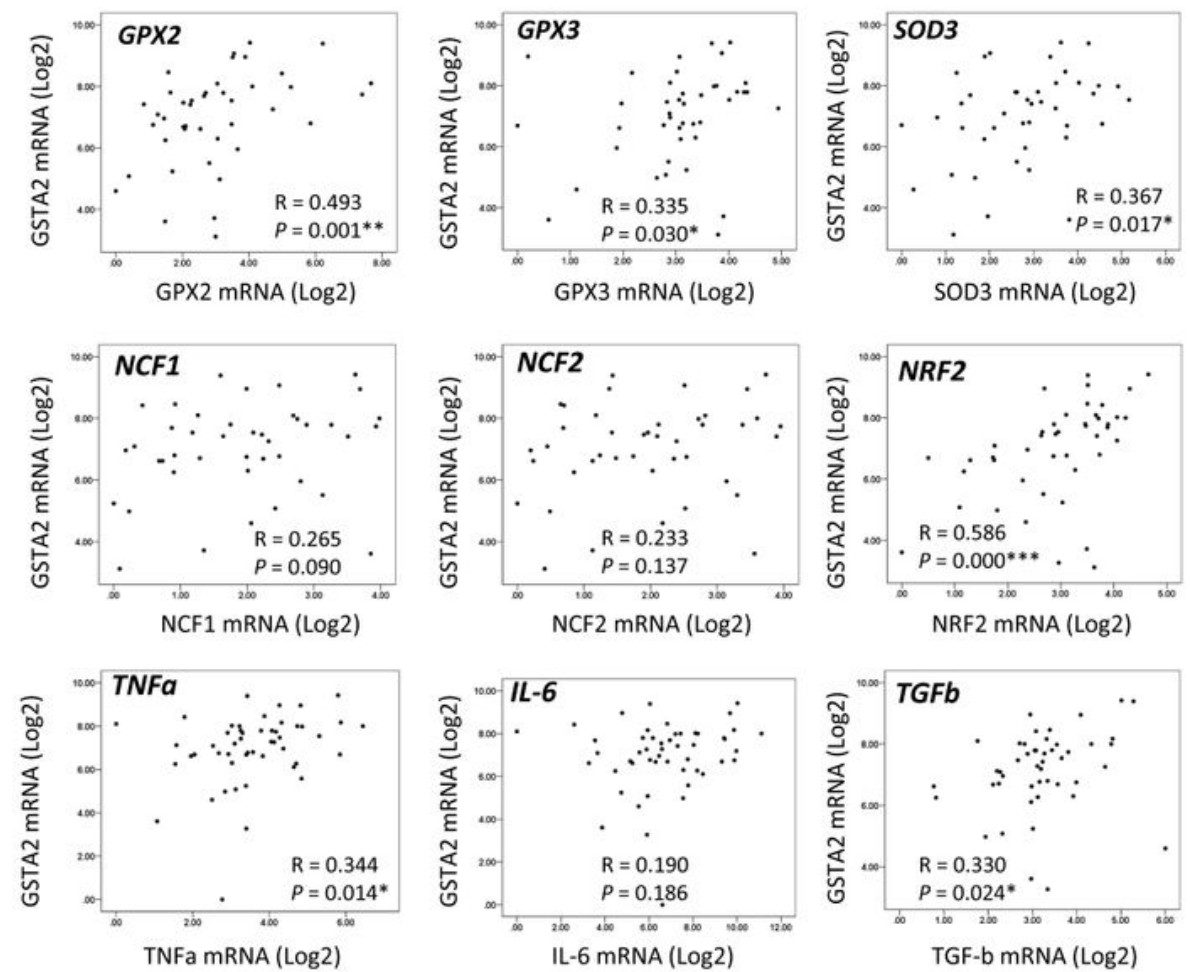

Fig. 1

\section{Figure 1}

Expression analysis of hepatic GSTA2 at 2-hours after liver transplantation. a Expression level of hepatic GSTA2 mRNA in the healthy donors and in the recipients at 2-hour after liver transplantation. b Comparison of post-LT 2-hour hepatic GSTA2 mRNA between recipients with and without post-LT HCC recurrence. c The expression level of hepatic GSTA2 mRNA in LDLT recurrent recipients and in DDLT nonrecurrent recipients. $d$ IHC analysis of GSTA2 protein between post-LT recurrent and non-recurrent 
recipients. Recur, post-LT HCC recurrence; Non-Recur, without post-LT HCC recurrence. e Correlation analysis of post-LT hepatic GSTA2 mRNA and ROS-associated genes (GPX2, GPX3, SOD3, NCF1, NCF2 and NRF2) and injury-associated genes (TNFa, IL-6 and TGFb). * $\mathrm{P}<0.05 ; * *, \mathrm{P}<0.01$.

A

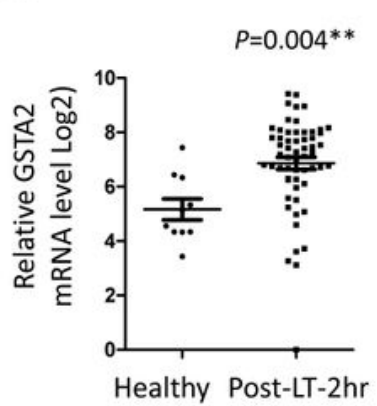

B

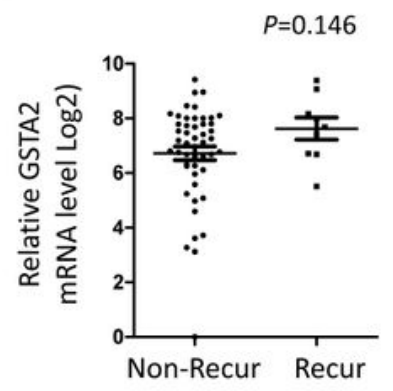

C

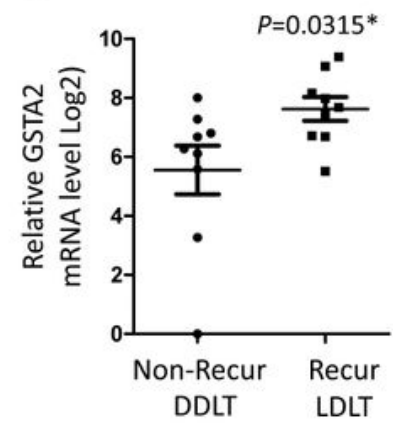

D

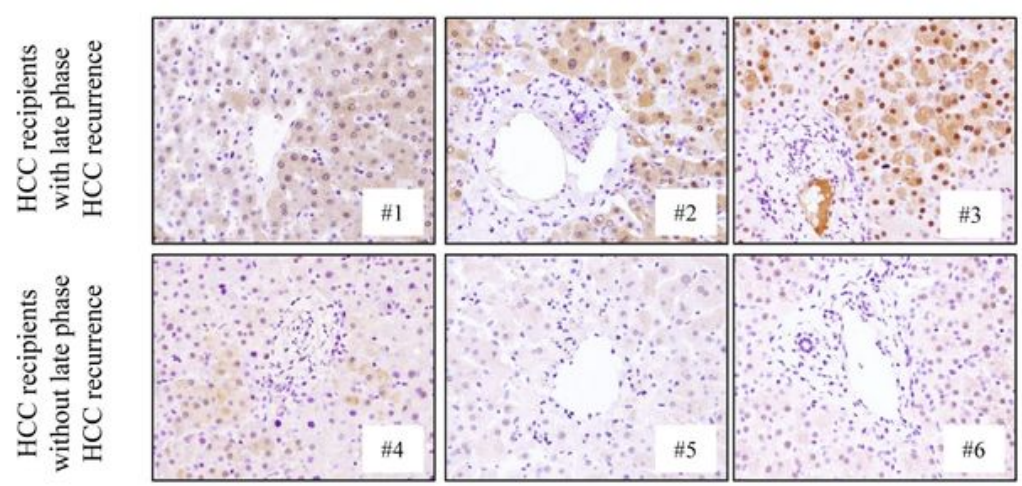

E
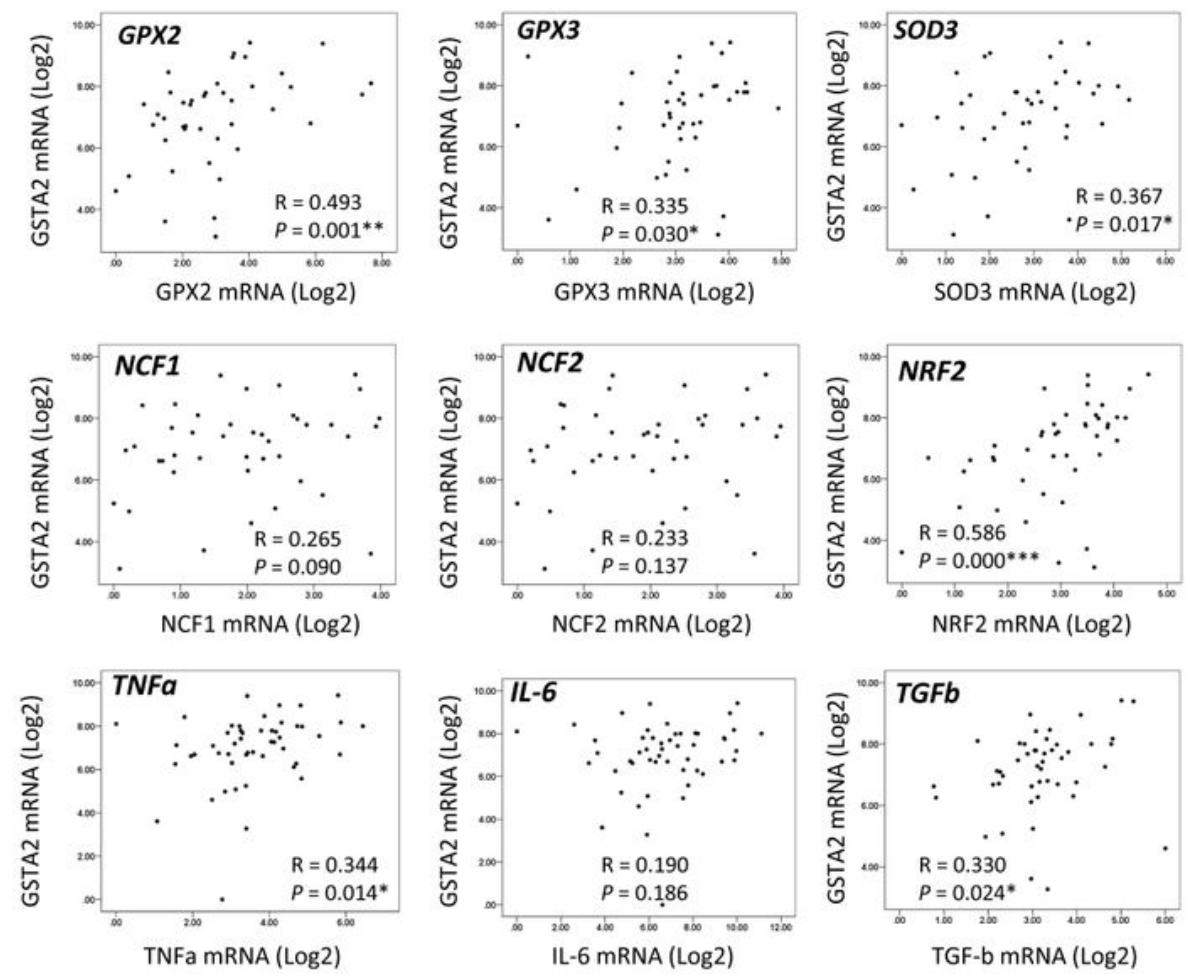

Fig. 1

\section{Figure 1}

Expression analysis of hepatic GSTA2 at 2-hours after liver transplantation. a Expression level of hepatic GSTA2 mRNA in the healthy donors and in the recipients at 2-hour after liver transplantation. b 
Comparison of post-LT 2-hour hepatic GSTA2 mRNA between recipients with and without post-LT HCC recurrence. $\mathrm{c}$ The expression level of hepatic GSTA2 mRNA in LDLT recurrent recipients and in DDLT nonrecurrent recipients. $d \mathrm{IHC}$ analysis of GSTA2 protein between post-LT recurrent and non-recurrent recipients. Recur, post-LT HCC recurrence; Non-Recur, without post-LT HCC recurrence. e Correlation analysis of post-LT hepatic GSTA2 mRNA and ROS-associated genes (GPX2, GPX3, SOD3, NCF1, NCF2 and NRF2) and injury-associated genes (TNFa, IL-6 and TGFb). *, P $<0.05 ; * *, P<0.01$.

A

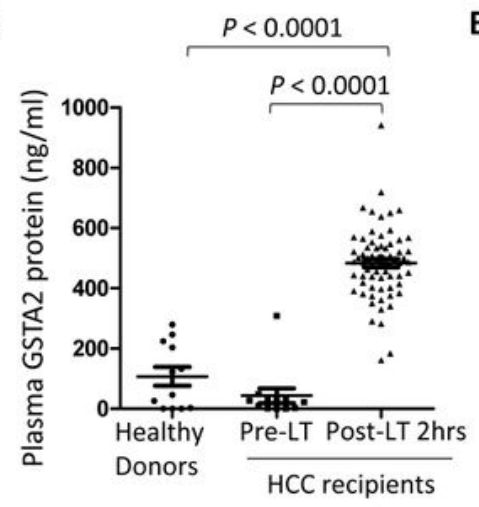

D

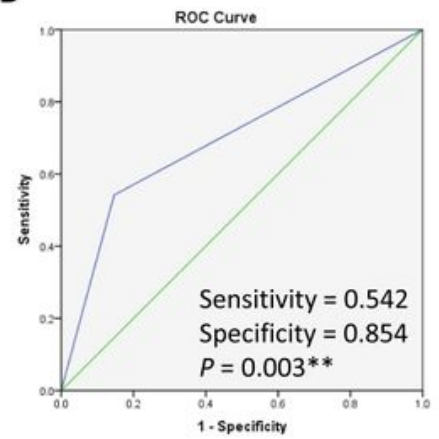

B

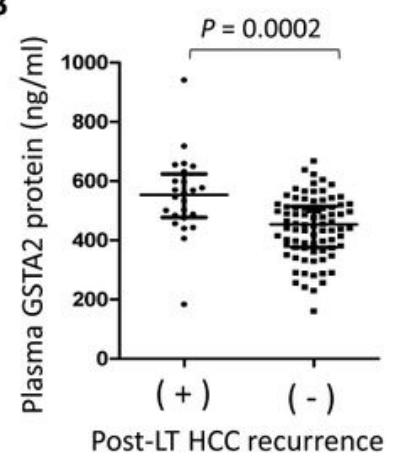

E

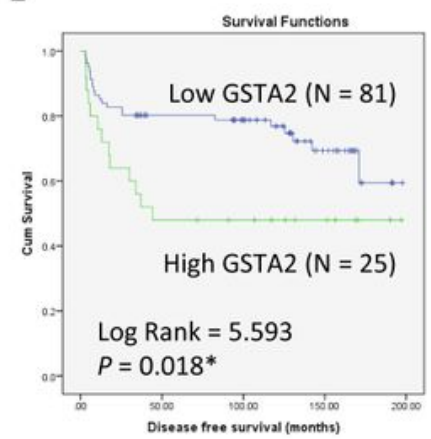

C

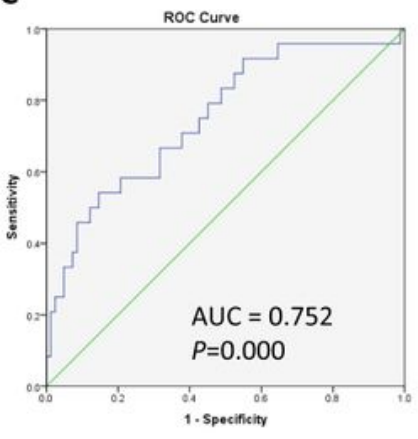

$\mathbf{F}$

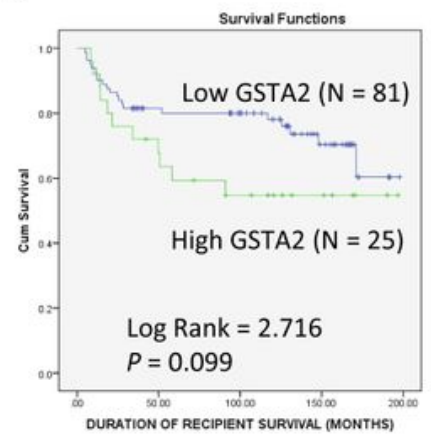

G

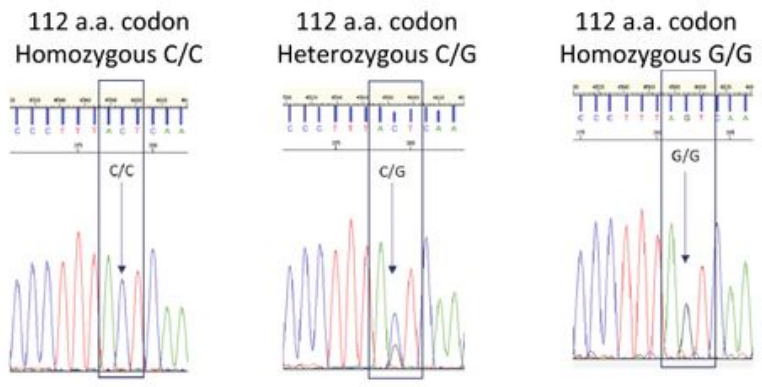

H
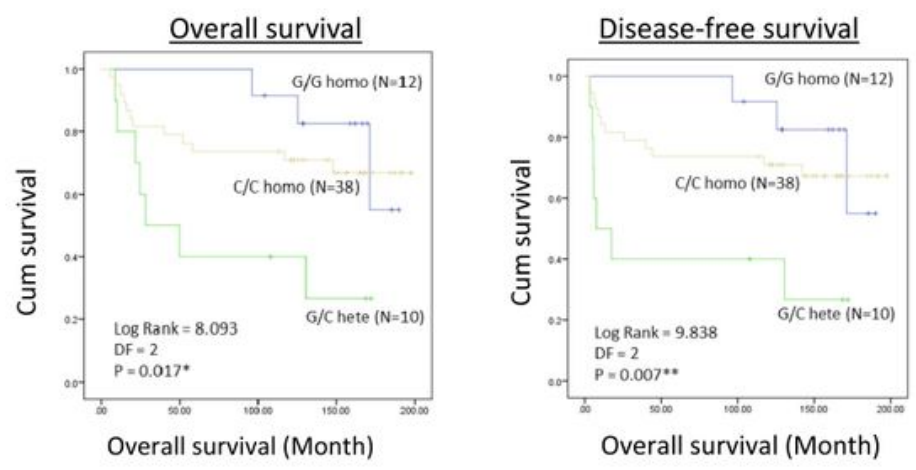

Fig. 2 
Post-liver transplantation early phase GSTA2 associated with late phase HCC recurrence. a The concentration of plasma GSTA2 protein in healthy donors and in pre-transplantation (Pre-LT) and in posttransplantation early phase (Pre-LT 2hrs) of HCC recipients. b The level of early-phase plasma GSTA2 protein in Recurrent recipients was significantly higher than in non-recurrence group. c ROC analysis of post-transplant early-phase plasma GSTA2 protein in predicting post-transplant HCC recurrence. $d$ ROC analysis of High plasma GSTA2 protein in predicting HCC recurrence after liver transplantation. e KaplanMeier analysis of plasma GSTA2 in disease-free survival of HCC recipients after liver transplantation. $f$ Kaplan-Meier analysis of plasma GSTA2 in overall survival of HCC recipients after liver transplantation. $g$ Sanger sequencing chromatographs of C335G homozygous and heterozygous alleles in GSTA2 coding sequencing. h Kaplan-Meier analysis of G335C SNP homozygosity and homozygosity of GSTA2 coding sequencing in the transplanted liver in predicting overall and disease-free survival of HCC recipients after liver transplantation. *, $\mathrm{P}<0.05$; $* *, \mathrm{P}<0.01$. 
A

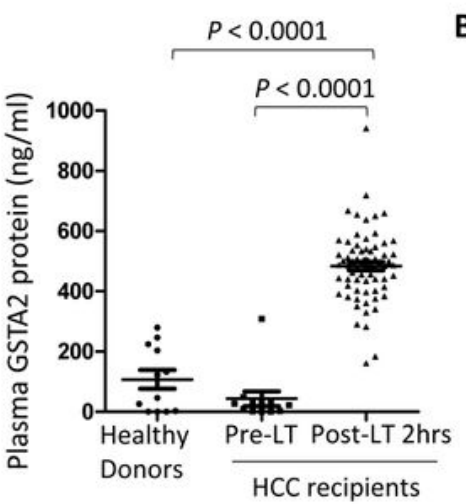

D

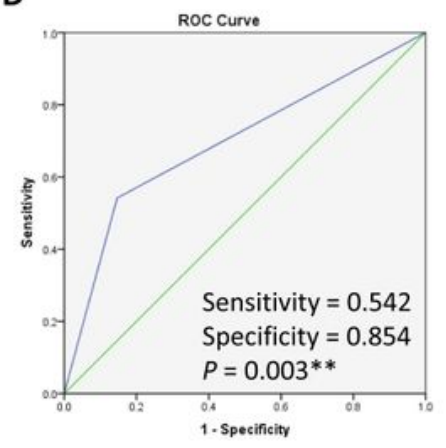

E
B

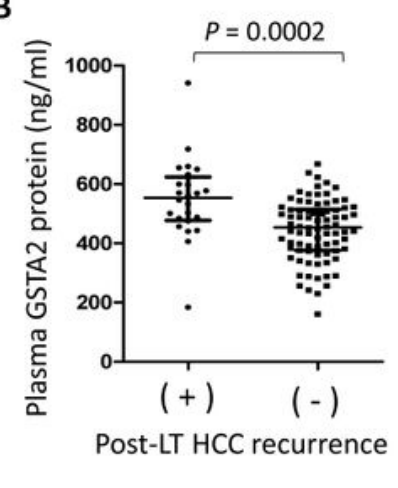

C
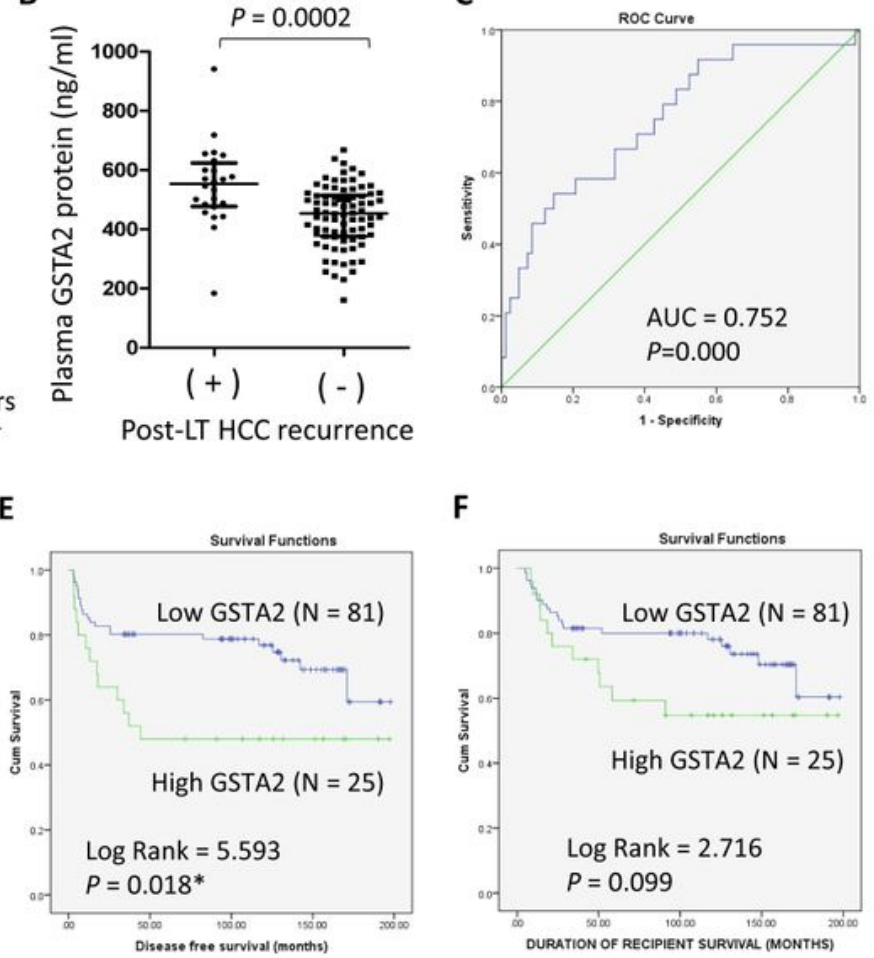

F

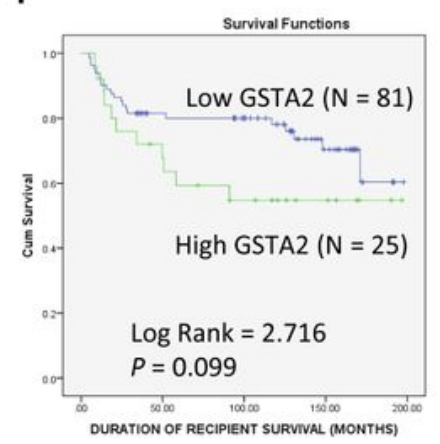

G

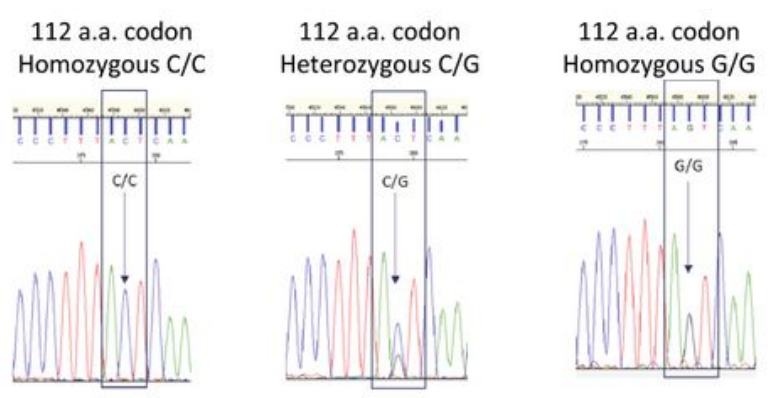

H
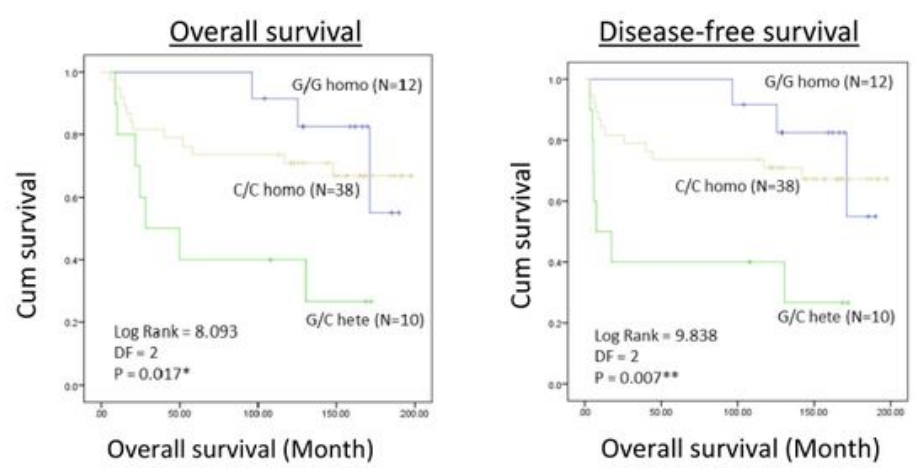

Fig. 2

\section{Figure 2}

Post-liver transplantation early phase GSTA2 associated with late phase HCC recurrence. a The concentration of plasma GSTA2 protein in healthy donors and in pre-transplantation (Pre-LT) and in posttransplantation early phase (Pre-LT 2hrs) of HCC recipients. b The level of early-phase plasma GSTA2 protein in Recurrent recipients was significantly higher than in non-recurrence group. c ROC analysis of post-transplant early-phase plasma GSTA2 protein in predicting post-transplant HCC recurrence. d ROC 
analysis of High plasma GSTA2 protein in predicting HCC recurrence after liver transplantation. e KaplanMeier analysis of plasma GSTA2 in disease-free survival of HCC recipients after liver transplantation. $f$ Kaplan-Meier analysis of plasma GSTA2 in overall survival of HCC recipients after liver transplantation. $g$ Sanger sequencing chromatographs of C335G homozygous and heterozygous alleles in GSTA2 coding sequencing. h Kaplan-Meier analysis of G335C SNP homozygosity and homozygosity of GSTA2 coding sequencing in the transplanted liver in predicting overall and disease-free survival of $\mathrm{HCC}$ recipients after liver transplantation. *, $\mathrm{P}<0.05 ; * \star, \mathrm{P}<0.01$.

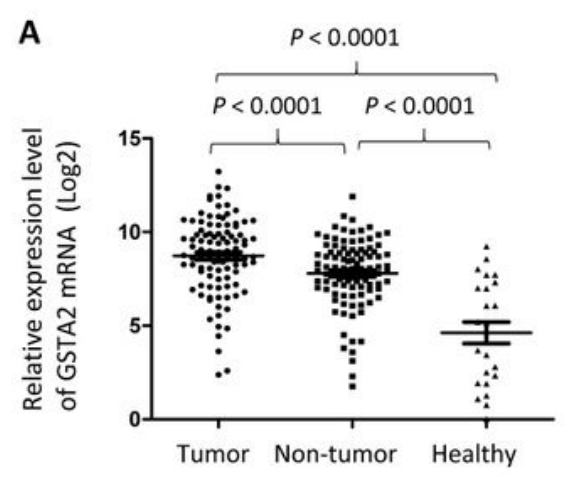

C
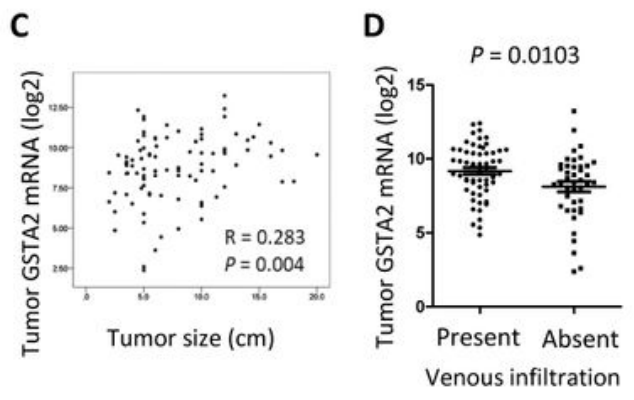

G
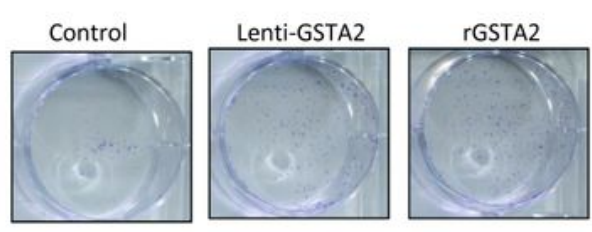

H

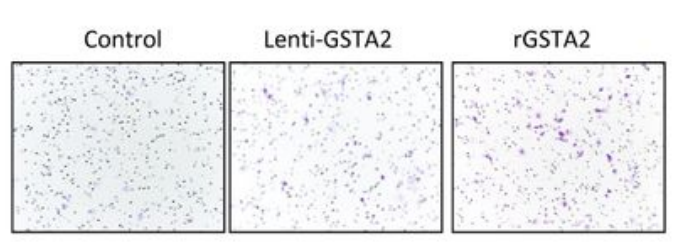

I

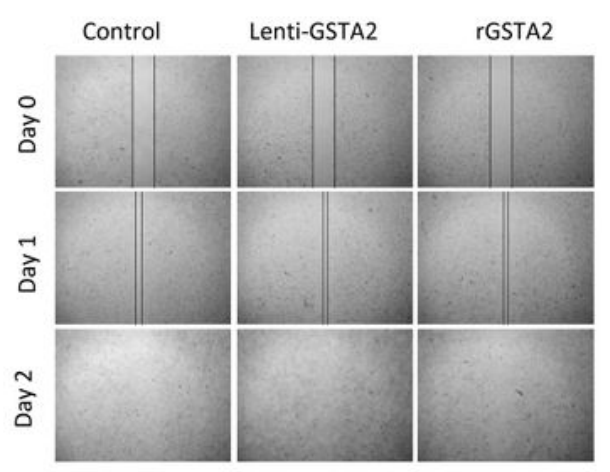

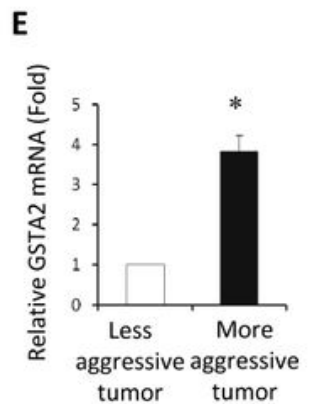

F
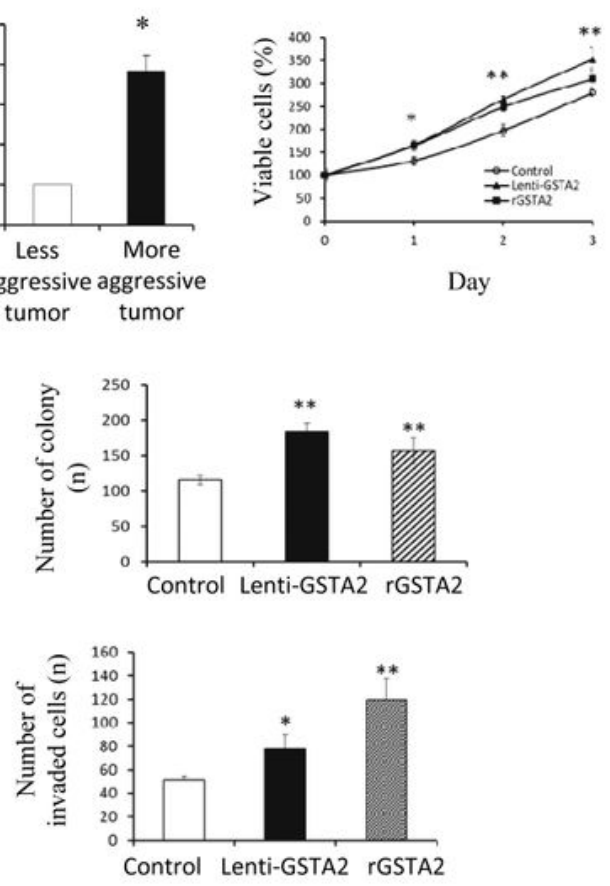

J

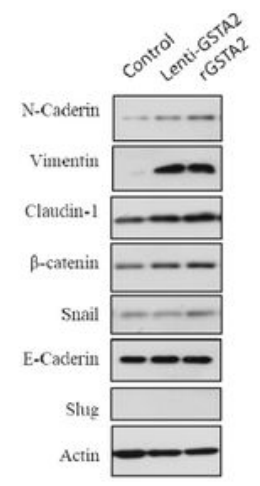

Fig. 3 


\section{Figure 3}

The expression and functions of GSTA2 in HCCs. a Expression of GSTA2 mRNA in the tumor (T) and nontumor (NT) liver tissues of HCC patients, and in the liver tissues of healthy donors. b Western blot analysis of GSTA2 protein in paired tumor (T) and non-tumor (NT) tissues of HCC patients. c The correlation analysis of the expression level of tumoral GSTAs mRNA and tumor size of human HCCs. $d$ The expression of GSTA2 mRNA and protein among different HCC cell lines. e The expression level of tumoral GSTA2 mRNAs between less aggressive and more aggressive tumors after liver transplantation in rat. $\mathrm{f}$ MTT assay of HCC cells after endogenously over-expressing GSTA2 by lentivirus (Lent-GSTA2) or administrating human recombinant GSTA2 protein (rGSTA2). g Colony-forming assay. h Matrigel invasion assay. i Wound healing migration assay. j Western blot analysis of EMT-associated proteins. Control, Hep3B-control cells; Lenti-GSTA2, Hep3B-LentiGSTA2 cells; rGSTA2, human recombinant GSTA2 protein, *, $\mathrm{P}<0.05 ; * \star, \mathrm{P}<0.01$. 
A

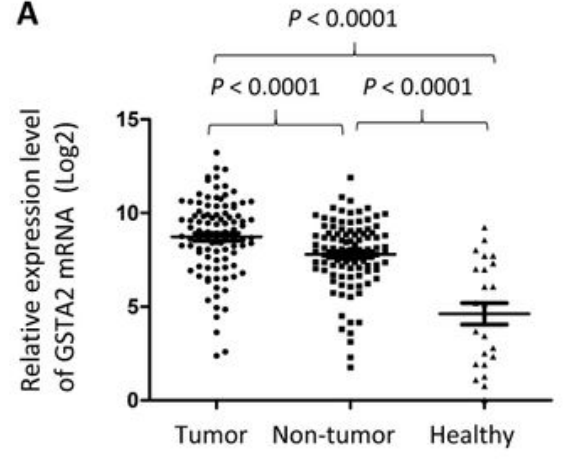

C
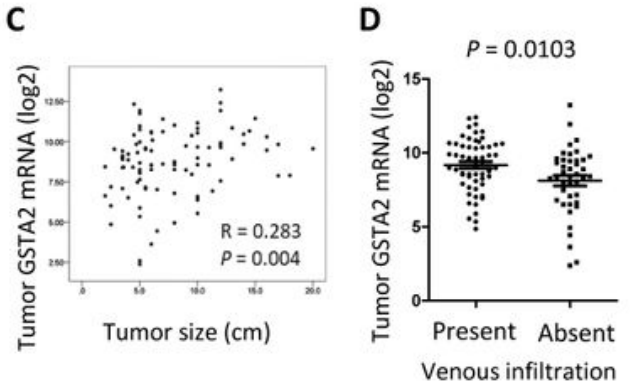

G
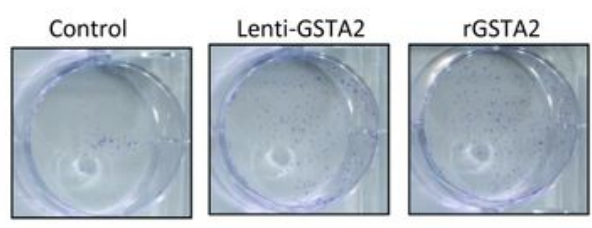

H

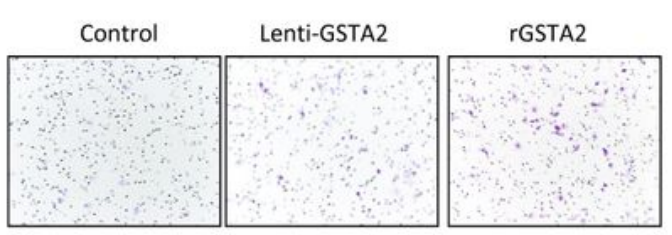

I

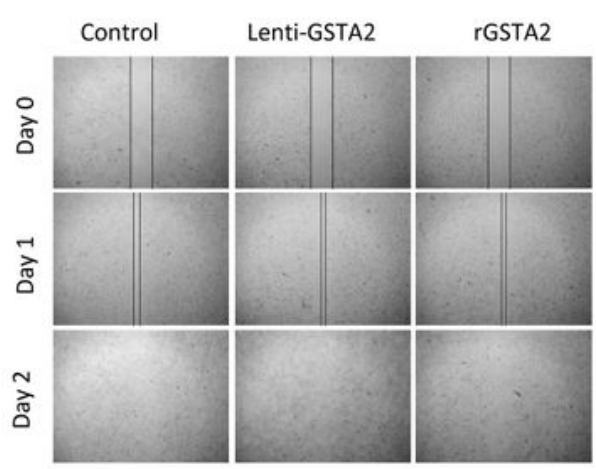

E

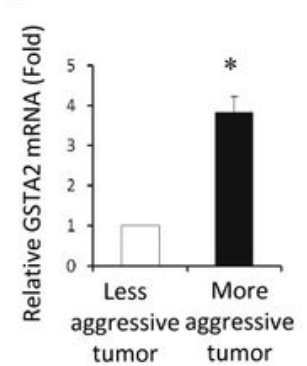

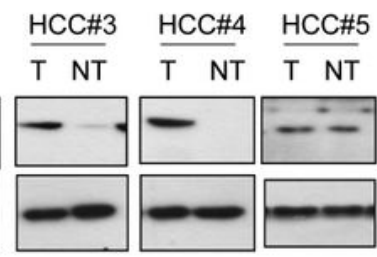

$\mathbf{F}$
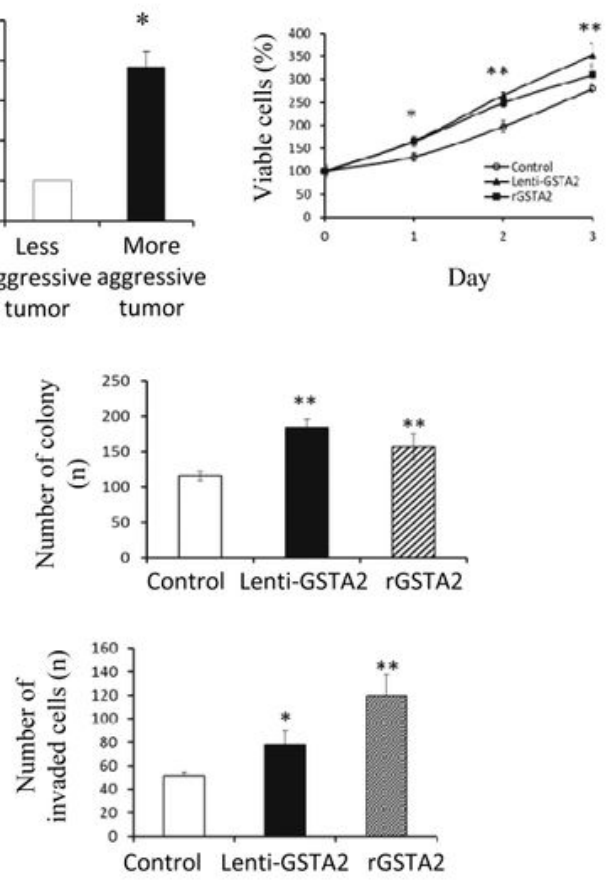

J

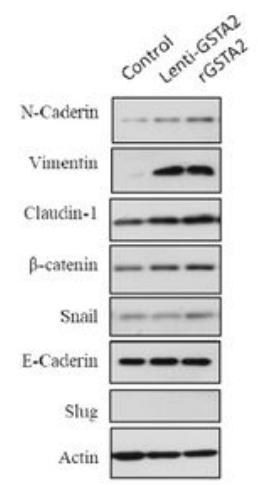

Fig. 3

\section{Figure 3}

The expression and functions of GSTA2 in HCCs. a Expression of GSTA2 mRNA in the tumor (T) and nontumor (NT) liver tissues of HCC patients, and in the liver tissues of healthy donors. b Western blot analysis of GSTA2 protein in paired tumor (T) and non-tumor (NT) tissues of HCC patients. c The correlation analysis of the expression level of tumoral GSTAs mRNA and tumor size of human HCCs. $d$ The expression of GSTA2 mRNA and protein among different HCC cell lines. e The expression level of 
tumoral GSTA2 mRNAs between less aggressive and more aggressive tumors after liver transplantation in rat. $\mathrm{f}$ MTT assay of HCC cells after endogenously over-expressing GSTA2 by lentivirus (Lent-GSTA2) or administrating human recombinant GSTA2 protein (rGSTA2). g Colony-forming assay. h Matrigel invasion assay. i Wound healing migration assay. j Western blot analysis of EMT-associated proteins. Control, Hep3B-control cells; Lenti-GSTA2, Hep3B-LentiGSTA2 cells; rGSTA2, human recombinant GSTA2 protein, *, $\mathrm{P}<0.05 ; \star \star, \mathrm{P}<0.01$.

A

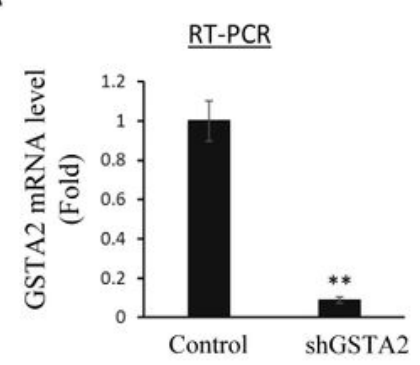

C
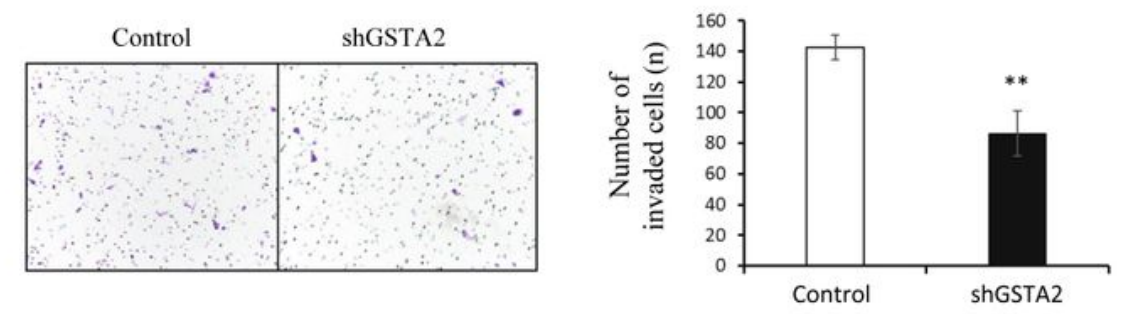

D

Tumor-bearing mice

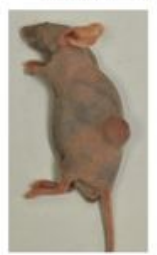

Control

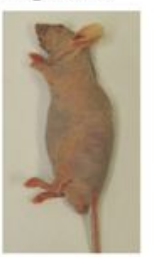

shGSTA2
Explanted tumor

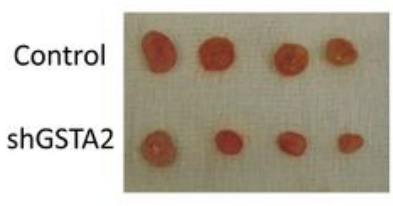

B

Western blot

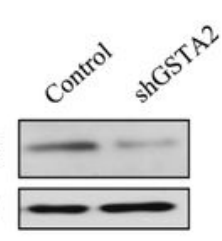

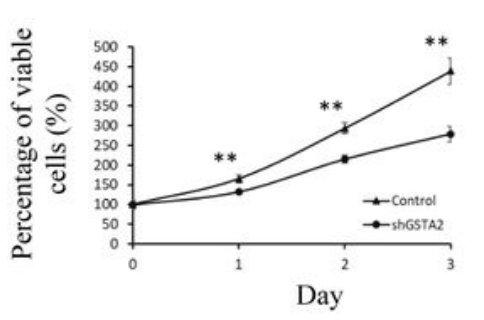

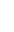

ton 
Suppression of GSTA2 expression significantly inhibit the in the growth and metastasis of MHCC97L. a Stable GSTA2-suppressing HCC cells exhibited significant down-regulation of GSTA2 mRNA and protein. b MTT proliferation assay for control and GSTA2-suppressing HCC cells. c Matrigel invasion assay for control and GSTA2-suppressing HCC cells. d H\& E staining of lung tissues in Metastatic tumor The dashed circle indicates the presence of HCC tumor in the lung. Control, MHCC97L-shControl stable cells; shGSTA2, MHCC97L-shGSTA2 stable cells; NS, no significance; *, $P<0.05 ; * \star, P<0.01$.

A

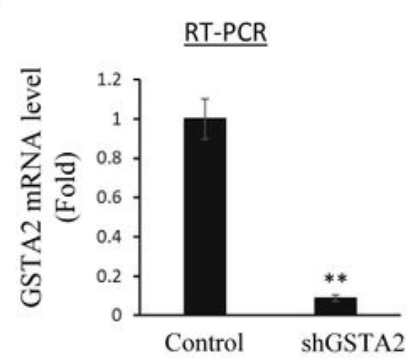

C
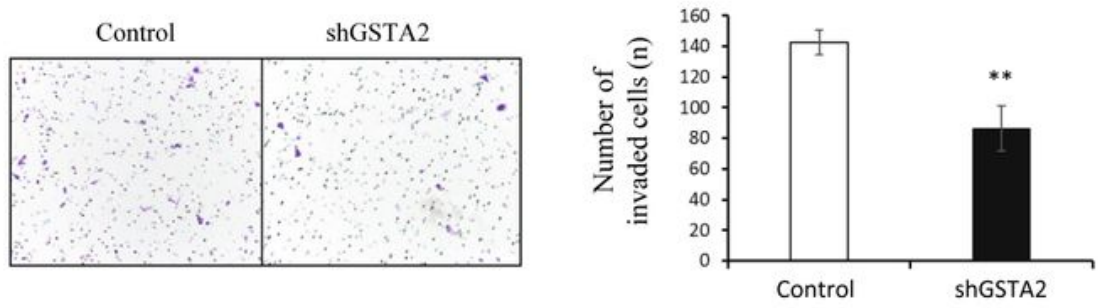

D
Tumor-bearing mice

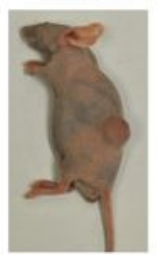

Control

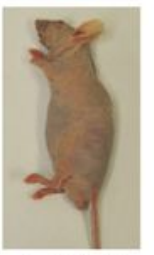

ShGSTA2
Explanted tumor

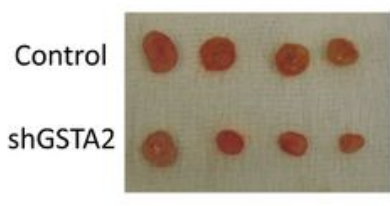

B

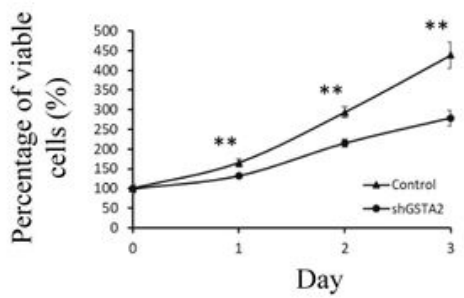

ShGSTA2
E

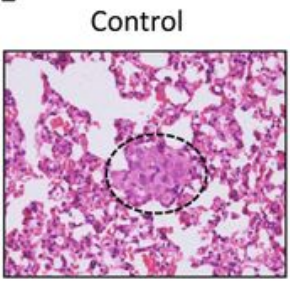
ShGSTA2

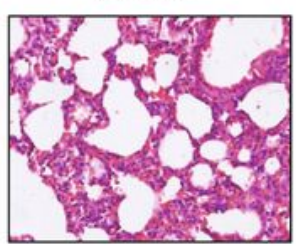

\begin{tabular}{|l|c|c|c|}
\hline & Control & shGSTA & $\begin{array}{c}\boldsymbol{P} \\
\text { value }\end{array}$ \\
\hline $\begin{array}{l}\text { Number of } \\
\text { nude mice } \\
\text { with lung } \\
\text { metastasis }\end{array}$ & $\begin{array}{c}3 / 8 \\
(37.5 \%)\end{array}$ & $0 / 8$ & $N S$ \\
\hline
\end{tabular}

Fig. 4 
Suppression of GSTA2 expression significantly inhibit the in the growth and metastasis of MHCC97L. a Stable GSTA2-suppressing HCC cells exhibited significant down-regulation of GSTA2 mRNA and protein. b MTT proliferation assay for control and GSTA2-suppressing HCC cells. c Matrigel invasion assay for control and GSTA2-suppressing HCC cells. $\mathrm{d}$ H\& E staining of lung tissues in Metastatic tumor The dashed circle indicates the presence of HCC tumor in the lung. Control, MHCC97L-shControl stable cells; shGSTA2, MHCC97L-shGSTA2 stable cells; NS, no significance; ${ }^{*}, \mathrm{P}<0.05 ; * \star, P<0.01$.

A

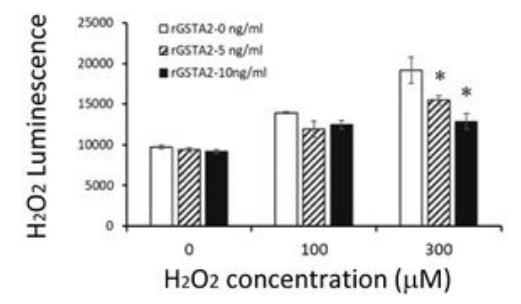

B

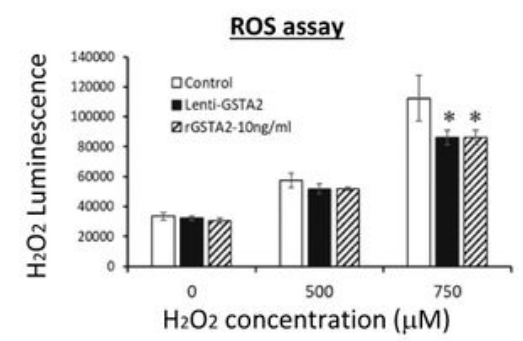

MTT viable assay
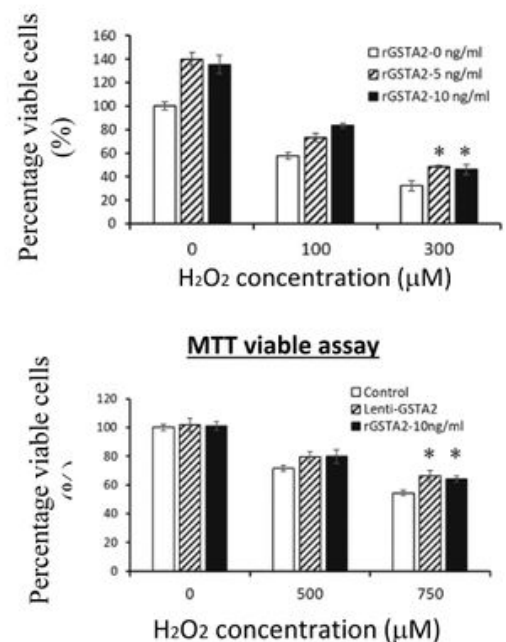

$\mathrm{H}_{2} \mathrm{O}_{2}$ concentration ( $\left.\mu \mathrm{M}\right)$
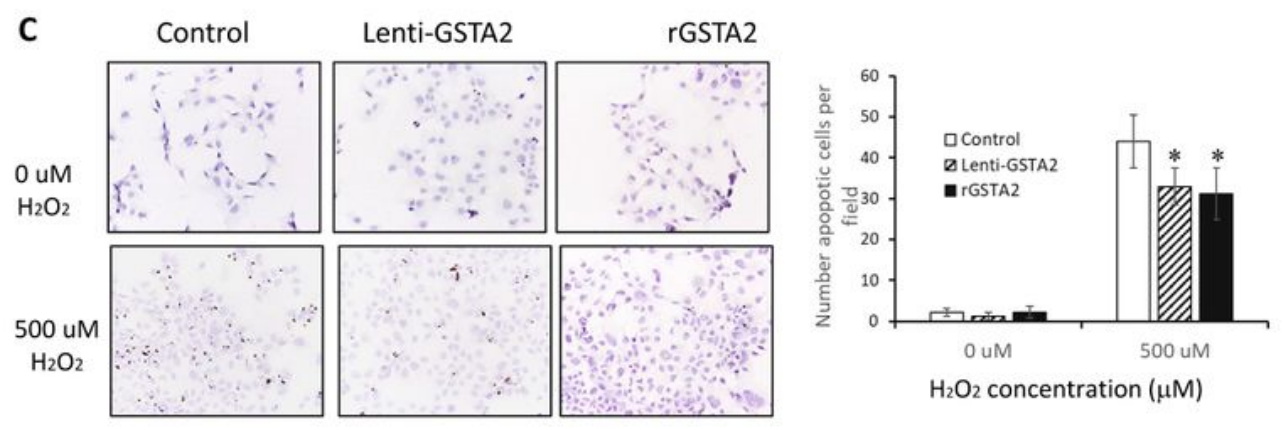

D

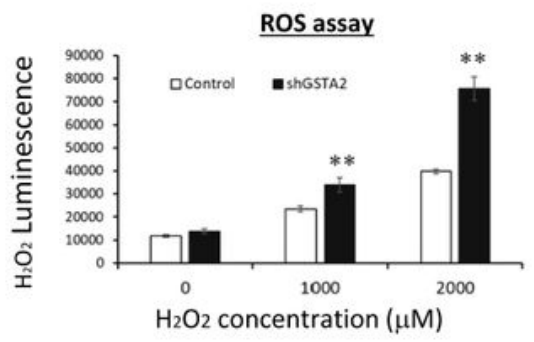

MTT viable assay
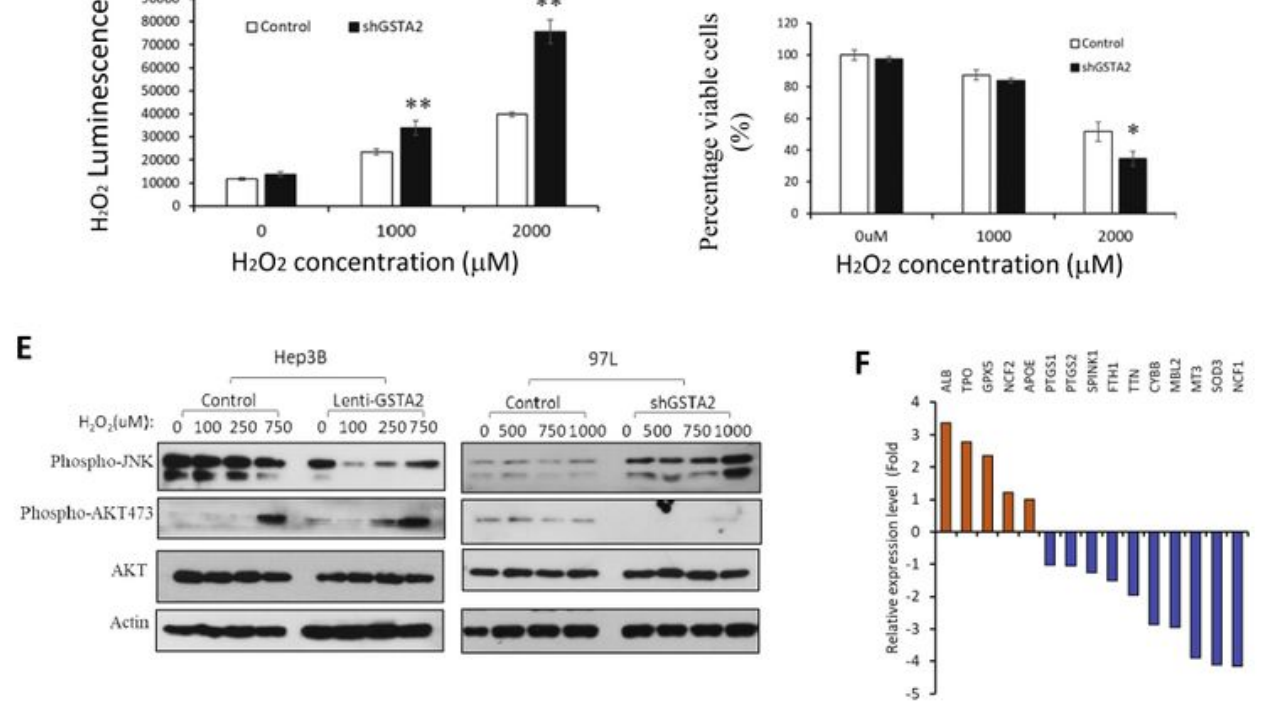

Fig. 5

Figure 5 
GSTA2 protected normal liver and HCC cells against high-ROS induced damage. a ROS assay and MTT assay of normal liver cells treated with different concentrations of recombinant GSTA2 protein (rGSTA2) under different concentration of H2O2. b ROS assay and MTT assay of Hep3B cells with upregulated expression of GSTA2 (Lenti-GSTA2) or administration of human recombinant GSTA2 protein (rGSTA2) under different concentrations of H2O2. c TUNEL apoptosis assay of Hep3B cells with upregulated expression of GSTA2 (Lenti-GSTA2) or administration of human recombinant GSTA2 protein (rGSTA2) under $\mathrm{H} 2 \mathrm{O} 2$ condition. d ROS assay and MTT assay for 97L-Control and 97L-shGSTA2 cells under different concentration of H2O2. e Western blot analysis of JNK and AKT pathway in GSTA2overexpressing and GSTA2-suppressing HCC cells under H2O2 conditions. f Differentially expressed ROSassociated genes by RT2 PCR array analysis in MHCC97L-shGSTA2 cells and MHCC97L-control cells under $\mathrm{H} 2 \mathrm{O} 2$ condition. ${ }^{*}, \mathrm{P}<0.05$; $* \star, \mathrm{P}<0.01$. 
A

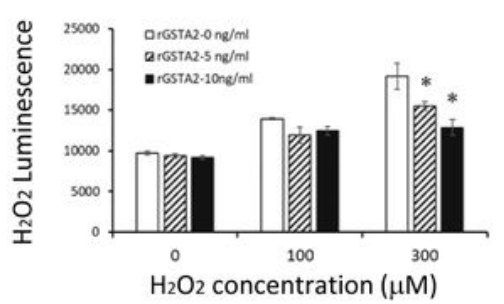

B

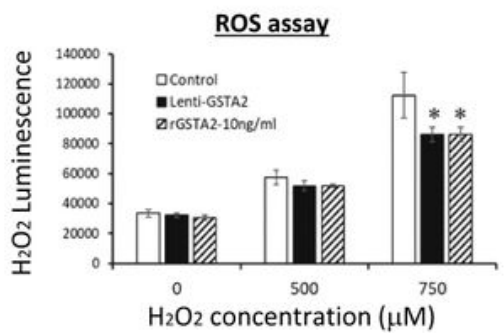

MTT viable assay
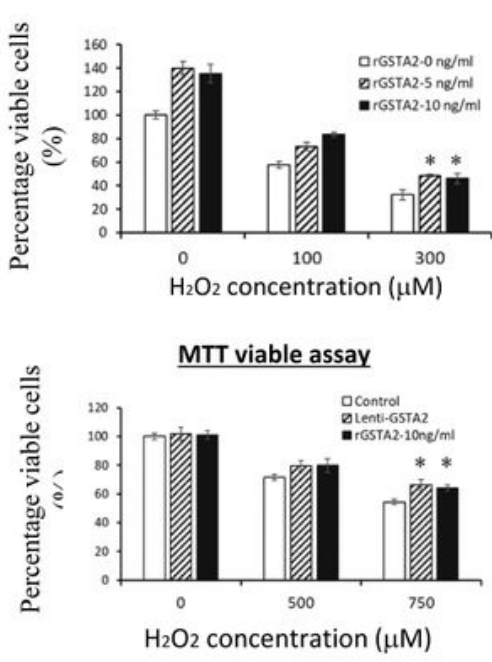

rGSTA2

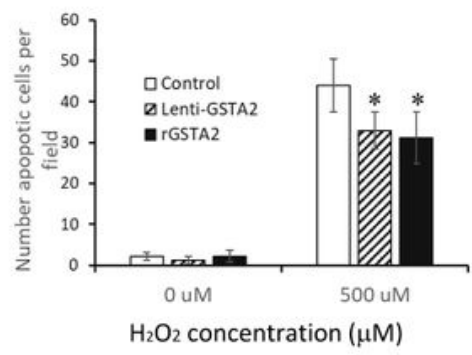

MTT viable assay

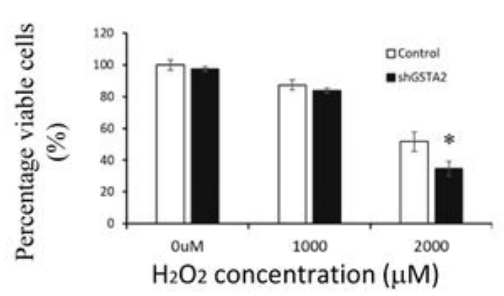

$\mathbf{F}$

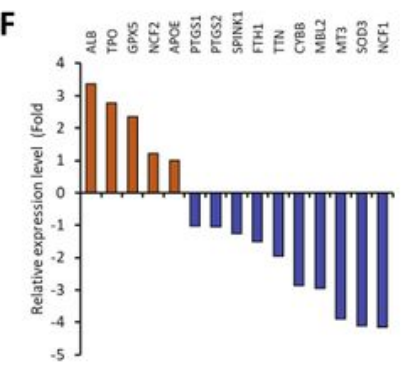

$\mathbf{E}$

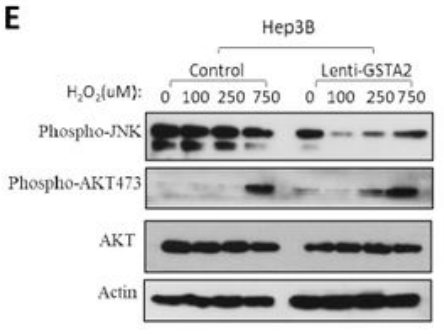

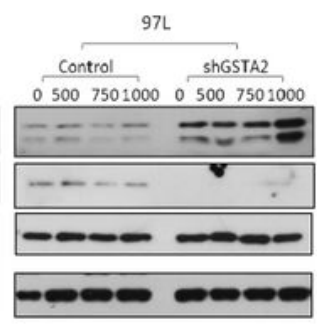

Fig. 5

\section{Figure 5}

GSTA2 protected normal liver and HCC cells against high-ROS induced damage. a ROS assay and MTT assay of normal liver cells treated with different concentrations of recombinant GSTA2 protein (rGSTA2) under different concentration of H2O2. b ROS assay and MTT assay of Hep3B cells with upregulated expression of GSTA2 (Lenti-GSTA2) or administration of human recombinant GSTA2 protein (rGSTA2) under different concentrations of H2O2. c TUNEL apoptosis assay of Hep3B cells with upregulated 
expression of GSTA2 (Lenti-GSTA2) or administration of human recombinant GSTA2 protein (rGSTA2) under $\mathrm{H} 2 \mathrm{O} 2$ condition. d ROS assay and MTT assay for 97L-Control and 97L-shGSTA2 cells under different concentration of H2O2. e Western blot analysis of JNK and AKT pathway in GSTA2overexpressing and GSTA2-suppressing HCC cells under H2O2 conditions. f Differentially expressed ROSassociated genes by RT2 PCR array analysis in MHCC97L-shGSTA2 cells and MHCC97L-control cells under $\mathrm{H} 2 \mathrm{O} 2$ condition. * $\mathrm{P}<0.05 ; * \star, \mathrm{P}<0.01$.

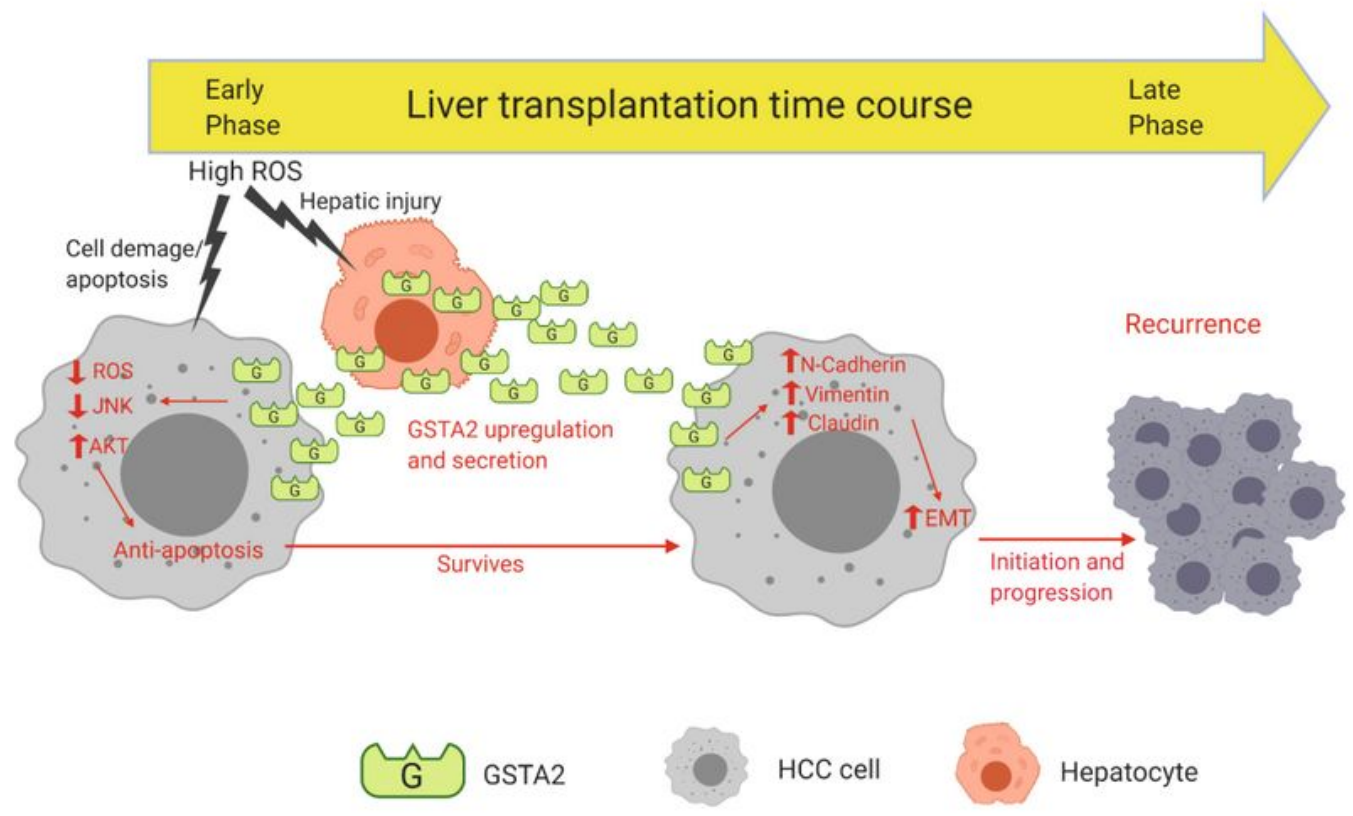

Fig. 6

Figure 6 
The proposed mechanism of GSTA2 in promoting HCC recurrence after liver transplantation. High ROS level resulted from I/R injury at early phase after liver transplantation causes cell damage and apoptosis on HCC cells. GSTA2 is induced and upregulated by high ROS and hepatic injury at early phase and secreted in the circulation. High level of GSTA2 provides anti-oxidative effect to protect the HCC cells against the high-ROS-induced cell damage and apoptosis. At the later time point after liver transplantation when the I/R injury is recovered, high level of GSTA2 can activate the EMT-associated proteins to promote HCC initiation and progression.

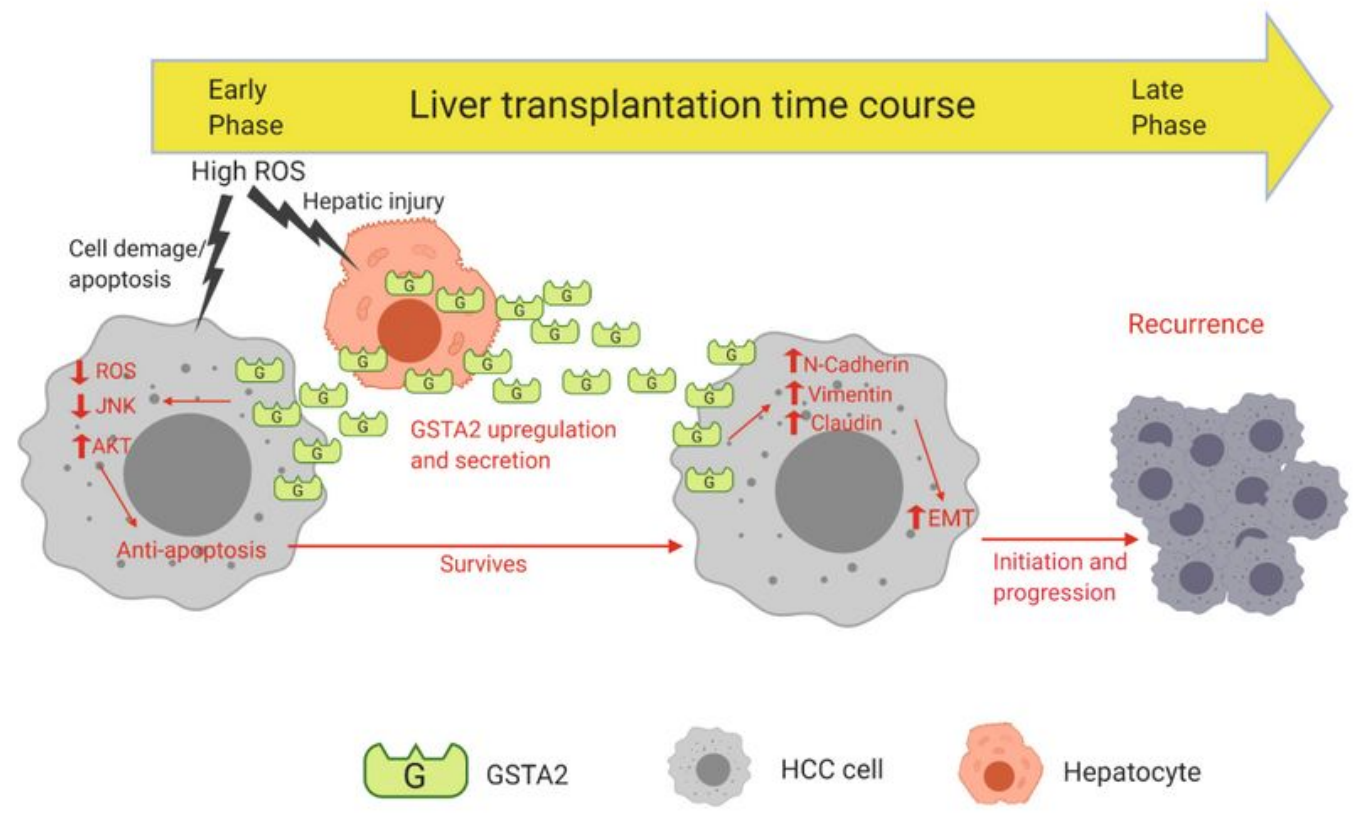

Fig. 6 


\section{Figure 6}

The proposed mechanism of GSTA2 in promoting HCC recurrence after liver transplantation. High ROS level resulted from I/R injury at early phase after liver transplantation causes cell damage and apoptosis on HCC cells. GSTA2 is induced and upregulated by high ROS and hepatic injury at early phase and secreted in the circulation. High level of GSTA2 provides anti-oxidative effect to protect the HCC cells against the high-ROS-induced cell damage and apoptosis. At the later time point after liver transplantation when the I/R injury is recovered, high level of GSTA2 can activate the EMT-associated proteins to promote HCC initiation and progression.

\section{Supplementary Files}

This is a list of supplementary files associated with this preprint. Click to download.

- AdditionalFile2.docx

- AdditionalFile2.docx

- AdditionalFile1.docx

- AdditionalFile1.docx 